\title{
Exploring various metal-ligand coordination bond formation in elastomers: Mechanical performance and self-healing behavior
}

\author{
M. Das, S. Pal, K. Naskar ${ }^{*}$ \\ Rubber Technology Centre, Indian Institute of Technology Kharagpur, 721302 West Bengal, India
}

Received 12 December 2019; accepted in revised form 21 February 2020

\begin{abstract}
Dynamic covalent crosslinking such as disulfide bonds, Diels-Alder (DA) reactions are widely used for healing applications. Herein, we report a simple approach involving the metal-ligand reversible interactions in diverse nature, which helps in developing a robust and self-healable carboxylated nitrile (XNBR) rubber by employing low cost and the commercially obtainable materials. Self-healing performance and mechanical properties were organized by introducing the various metal-ligand domains into the XNBR rubber. The network of XNBR, in-situ cross-linked via metal-ligand complexes, consists of strong and weak coordination bonds. The strength of various metal-ligand modified coordination bonds, healing performance, and mechanical properties primarily depend on the type of metal ions. The Fourier transform infrared spectroscopy (FTIR) makes the various metal-ligand coordination bond formation into the XNBR rubber visible. The coordination crosslinked XNBR rubber with $4 \mathrm{phr}$ of $\mathrm{Zn}$ and Co metal ion exhibits high tensile strength $(4.3 \pm 0.6$ and $10.3 \pm 1.1 \mathrm{MPa})$ with excellent healing efficiency (100 and 88\%), which is far higher than the most reported non-covalent supramolecular modified elastomers. The various metal-ligand coordination bonds are fully reconstructed during the rebuilding process and exhibiting excellent self-healing property.
\end{abstract}

Keywords: mechanical properties, XNBR rubber, various metal-ligand bond, self-healing

\section{Introduction}

Rubber is a virtually incompressible material that exhibits high elasticity; its phenomenal flexibility is often explored in various applications such as, hoses, seals, tires, shock absorbers, etc. Natural rubber (NR), polybutadiene rubber (BR), ethylene-propylenediene rubber (EPDM), acrylonitrile-butadiene rubber (NBR), and styrene-butadiene (SBR) are some common examples of a widely used elastomer in day to day life [1]. In the recent developments over the past few decades, the idea of commercially adaptable characteristics that enable spontaneous healing or mending of damages in the rubbery product has gained tremendous popularity $[2,3]$. Rubbers with such attributes are popularly known as self-healing rubbers
$[3,4]$. Self-healing rubbers exhibit built-in ability to repair damage to themselves spontaneously. Such additional value to the rubbery materials is beneficial, especially taking into account that rubbers are prone to fatigue and environmental conditions. The self-healing characteristics enhance the longevity of rubber-based products [5].

Elastomers that posses self-healing ability can be broadly divided into two classes, i.e., autonomous [6-8] and non-autonomous self-healing rubbers [9]. The autonomous self-healing polymers follow a process very similar to that of a biological response [9], which does not require external intervention [10]. Polymers with a kind of encapsulated internal adhesives were the first synthetic materials to be reported 
as autonomous self-healing material in 2001 by White [6], Nancy Sottos, and colleagues from the University of Illinois [6]. After that, many other self-healing materials [11] were developed. On the other hand, the non-autonomous self-healing rubbers [12] require some form of external stimuli such as heat, light, mechanical, or chemical. Terryn et al. [13] and Habault et al. [14], have proposed the heat stimulated self-healing elastomers [13]. Moniruzzaman et al. [16] and Amamoto et al. [17] have suggested lightinduced self-healing rubbers, and Rekondo et al. [20] have worked on the mechanochemical self-healing elastomers $[14,15]$. Some specific interactions through noncovalent bonding such as hydrogen bonding [16], metal-ligand coordination [17-20], host-guest interactions [21, 22], ionic bonds [23$25]$, van der Waals forces, $\pi-\pi$ interactions, halogen bonding $[16,26]$, etc., and some dynamic covalent bonds like Diels-Alder [27-29], disulfide bonds [30], imine bonds, etc., are involved in the majority of the strategies for the development of self-healing elastomer. These specific interactions are collectively known by the term 'molecular recognition' [31, 32].

Experiments involving the concept of self-healing have been reported, but very few have worked on the challenges and limitations of developing the selfhealing elastomer [12] that possesses good healing efficiency and good mechanical strength. Inspired by Wang et al. [4], and Cheng et al. [33] it has been reported that the recyclability of dopamine grafted epoxidized nitrile rubber with $2.5 \mathrm{phr}$ of ferric chloride reached 8.93 MPa tensile strength. We report a simple preparation and testing a design for the structural rubbery materials that exhibit excellent robustness and good self-heal efficiency [34]. This study compares the effect of different types of metalligand coordination systems [35-37], introduced via general-purpose rubber equipment, on the mechanical properties and self-healing behavior of the rubbery material. Our self-healing experiments yield as much as $88 \%$ recovery of $10.3 \mathrm{MPa}$ tensile strength. We expect our approach (Figure 1) to apply to a wide variety of rubbers.

\section{Expérimental sections}

\subsection{Materials}

Carboxylated nitrile-butadiene rubber (XNBR, Kry$n a c^{\circledR} X 750$, by Lanxess, Germany), consisting of $7 \mathrm{wt} \%$ carboxylic group and $27 \mathrm{wt} \%$ acrylonitrile content, was directly used. Specific gravity and Mooney viscosity (ML 1+4 @ $100^{\circ} \mathrm{C}$ ) of the rubber was found to be 0.99 and 47 respectively. The metal salts, cobalt(II) nitrate hexahydrate $\left(\mathrm{Co}\left(\mathrm{NO}_{3}\right)_{2} \cdot 6 \mathrm{H}_{2} \mathrm{O}\right.$, $\mathrm{Co}^{2+}, \quad 98 \%$ ); nickel(II) nitrate hexahydrate $\left(\mathrm{Ni}\left(\mathrm{NO}_{3}\right)_{2} \cdot 6 \mathrm{H}_{2} \mathrm{O}, \mathrm{Ni}^{2+}, 98 \%\right)$; zinc(II) nitrate hexahydrate $\left(\mathrm{Zn}\left(\mathrm{NO}_{3}\right)_{2} \cdot 6 \mathrm{H}_{2} \mathrm{O}, \mathrm{Zn}^{2+}, 98 \%\right)$, were purchased from Sigma-Aldrich. The ligand, 2,6-diaminopyridine (DAP, 98\%) was purchased from Sigma-Aldrich; all reagents were analytical grade and used as received.

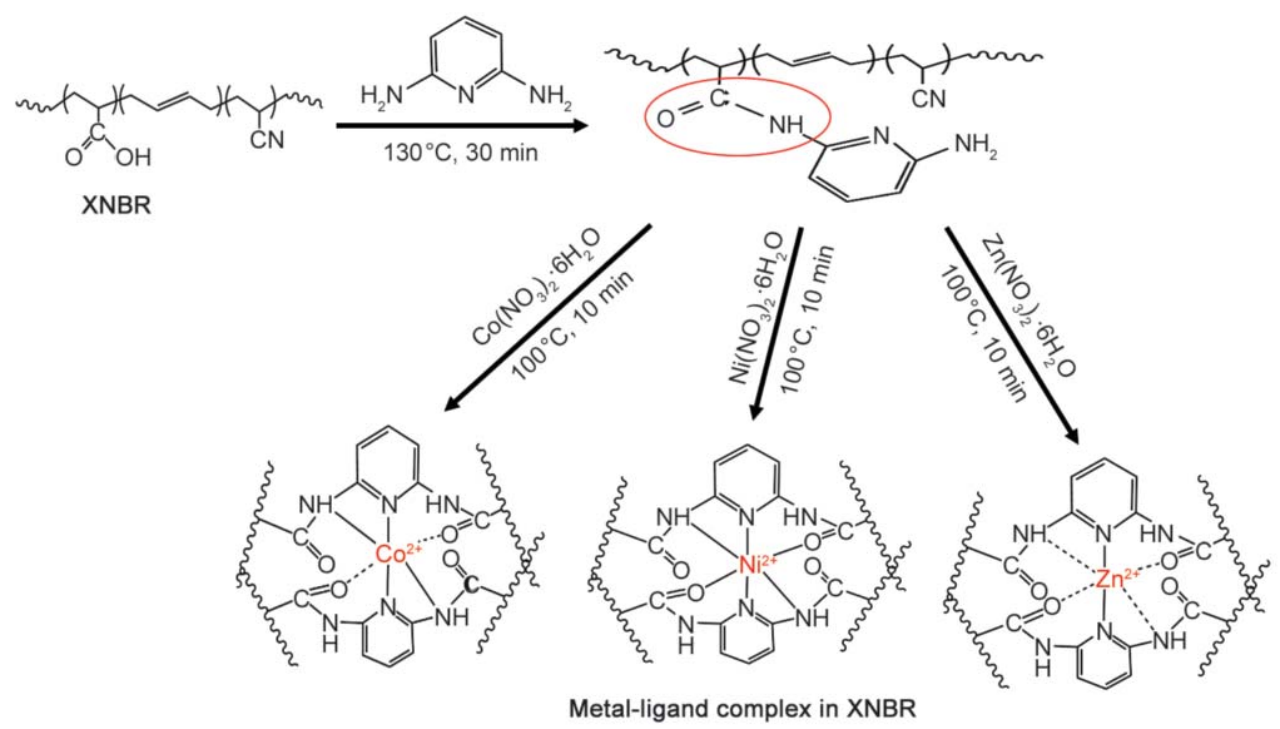

Figure 1. The proposed model of the multiple metal-ligand bonds in XNBR. The solid line indicates the strong metal-ligand bond and the dashed line indicates the weak metal-ligand bond. 


\subsection{Preparation of $X N B R-D A P-m e t a l$ ion complexes}

2,6-diaminopyridine, cobalt(II) nitrate hexahydrate, nickel(II) nitrate hexahydrate, and zinc(II) nitrate hexahydrate were mixed with carboxylated nitrile rubber(XNBR) in two successive steps, according to the compounding formulation (Table 1). First, XNBR and DAP (1:1-mole ratio $\mathrm{COOH}$ group in XNBR: DAP ligand, which was converted into phr) were mixed inside the chamber of an internal mixer (Thermo Haake Poly Lab oS Rheo Drive4) for $30 \mathrm{~min}$, at $130{ }^{\circ} \mathrm{C}$ and $60 \mathrm{rpm}$ rotor speed. Then the DAPXNBR compound was homogenized by a two-roll mixing mill (Polymix 110L, size 203×102 mm, Servitech $\mathrm{GmbH}$, Wustermark, Germany) for $2 \mathrm{~min}$. The amide linkage was brought about by DAP-carboxyl chemical reactions into the XNBR rubber, during this first step (as revealed by FT-IR analysis).

In the second step, different rubber compounds were prepared by mixing various metal salts with the aforementioned modified XNBR rubber. The ingredients were mixed inside the chamber of an internal mixer at $100^{\circ} \mathrm{C}$ for $10 \mathrm{~min}$ with a rotor speed of $60 \mathrm{rpm}$. After mixing, the rubber compounds were homogenized by a laboratory size two-roll mixing mill for $2 \mathrm{~min}$. Then, rubber compounds were compression molded at $170^{\circ} \mathrm{C}[33]$ and $5 \mathrm{MPa}$ pressure for $30 \mathrm{~min}$ by using a hydraulic press (Moore Hydraulic Press, England), and the molded specimens were cooled under pressure to protect the total dimensional stability. The final molded samples were subjected to various analyses, such as FT-IR spectroscopy, stressstrain, etc., to understand the effect of incorporation of metal salts towards the properties improvement and self-healing ability.

\subsection{Characterization}

\subsubsection{Fourier transform infrared (FTIR) spectroscopy}

The FTIR analysis was accomplished to find out the interactions in the rubber compounds. The spectra of

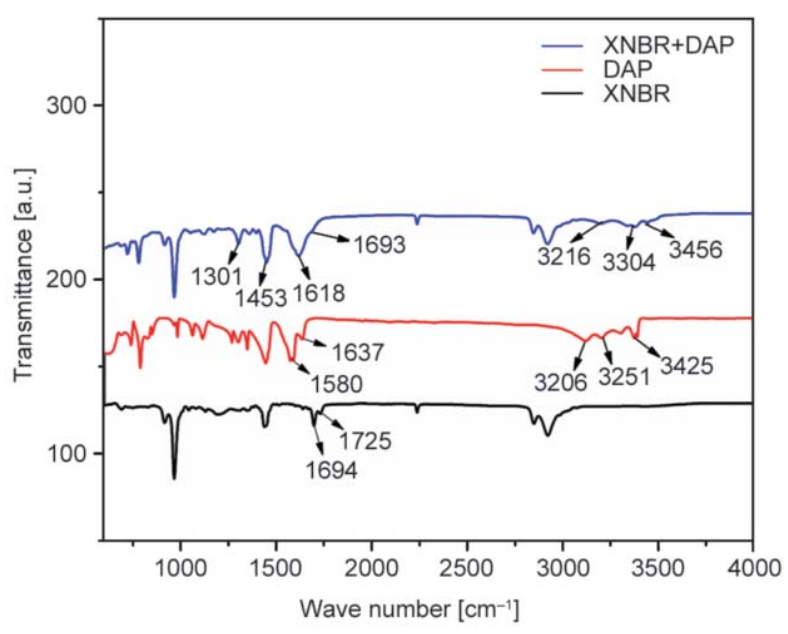

Figure 2. FTIR spectra of pristine XNBR, neat DAP ligand, and XNBR+DAP compound.

samples were obtained by using the Perkin Elmer spectrometer, over the wavenumber 500 to $4000 \mathrm{~cm}^{-1}$ range, and an attenuated total reflectance (ATR) mode setup. The number of scans for each sample was 8 .

The FTIR spectra of XNBR, DAP ligand, and $\mathrm{XNBR}+\mathrm{DAP}$ compounds were shown in Figure 2. In the case of pristine XNBR, the characteristic peaks at 2919 and $2844 \mathrm{~cm}^{-1}$ (not indicated in figure) correspond to the stretching vibrations of $\mathrm{CH}_{2}$ groups [38], the peak at $2234 \mathrm{~cm}^{-1}$ was ascribed to the $-\mathrm{CN}$ groups of the acrylonitrile moiety of XNBR [38], Peaks at 1725 and $1694 \mathrm{~cm}^{-1}$ correspond to the $-\mathrm{COOH}$ groups of the acrylic acid moiety of XNBR and $-\mathrm{C}=\mathrm{O}$ stretching vibration of carboxylic groups, respectively. Whereas, neat DAP ligand [39, 40], peaks at $3425,3251,3206,1637$, and $1580 \mathrm{~cm}^{-1}$ were attributed to the $-\mathrm{NH}$ asymmetric stretching, -NH symmetric stretching, $\mathrm{N}+-\mathrm{H}$ stretching vibrations, $-\mathrm{NH}$ bending vibrations of $\mathrm{NH}_{2}$ groups, and the $\mathrm{C}=\mathrm{C}$ stretching vibrations of free pyridine, respectively. After introducing the DAP ligand into XNBR rubber, a newly characteristic absorption peak at $1693 \mathrm{~cm}^{-1}$ (amide band [4] I) and $1618 \mathrm{~cm}^{-1}$ (amide band [4] II) (indicated in Figure 1) are due to the amide formation (-CO-NH-) between the $-\mathrm{COOH}$

Table 1. Formulations of all the rubber compounds.

\begin{tabular}{|l|c|c|c|c|c|}
\hline \multirow{2}{*}{ Sample name } & \multicolumn{5}{|c|}{$\begin{array}{c}\text { Ingredients } \\
\text { [phr] }\end{array}$} \\
\cline { 2 - 6 } & XNBR & DAP & $\mathbf{C o}\left(\mathbf{N O}_{3}\right)_{2} \cdot \mathbf{6 H}_{\mathbf{2}} \mathbf{O}$ & $\mathbf{N i}_{\left(\mathbf{N O}_{3}\right)_{2} \cdot \mathbf{6} \mathbf{H}_{2} \mathbf{O}}$ & $\mathbf{Z n}\left(\mathbf{N O}_{3}\right)_{2} \cdot \mathbf{6} \mathbf{H}_{2} \mathbf{O}$ \\
\hline $\mathrm{XNBR}+\mathrm{DAP}$ & 100 & 12 & - & - & - \\
\hline $\mathrm{XNBR}+\mathrm{DAP}+\mathrm{Co}^{2+}$ & 100 & 12 & 4 & - & - \\
\hline $\mathrm{XNBR}+\mathrm{DAP}+\mathrm{Ni}^{2+}$ & 100 & 12 & - & 4 & - \\
\hline $\mathrm{XNBR}+\mathrm{DAP}+\mathrm{Zn}^{2+}$ & 100 & 12 & - & - & 4 \\
\hline
\end{tabular}


group of XNBR and the $\mathrm{NH}_{2}$ of DAP ligand. The peak at $1453 \mathrm{~cm}^{-1}$ is observed of DAP ligand, which is the $\mathrm{C}=\mathrm{N}$ vibration modes of free pyridine and the exhibits at $1301 \mathrm{~cm}^{-1}$ is the $\mathrm{C}-\mathrm{N}$ stretching vibrations of free pyridine and the peaks at 3457,3304 and $3216 \mathrm{~cm}^{-1}$ attributes to the $-\mathrm{NH}$ asymmetric, symmetric and $\mathrm{N}+-\mathrm{H}$ stretching vibrations of the DAP ligand.

\subsubsection{Mechanical properties}

The tensile experiment of all samples was performed using a Universal Testing Machine (Hounsfield H25KS) apparatus, according to the ASTM D-412 standard. An extension rate of $500 \mathrm{~mm} / \mathrm{min}$ and room temperature conditions were used for the experiment. A dumbbell-shaped sample specimen, $20 \mathrm{~mm}$ gauge length and $3 \mathrm{~mm}$ width in dimension, was placed in the grips of the testing machine.

\subsubsection{Self-healing properties}

The self-healing experiment of all samples was performed using a Universal Testing Machine (UTM). The standard dumbbell-shaped samples were cut from the middle using a scissor into two separate pieces; the freshly cut surface of samples was held together inside a vacuum oven for various length of time ( 0.5 , $1,3,6,12$, and $24 \mathrm{~h}$ ). The healing efficiency of various samples was also studied at different temperatures (RT, 40,60 and 80C). The self-healing efficiency [34] $(\eta)$ is defined as the ratio of the tensile strength of the healed sample ( $\sigma$ healed) to the virgin sample ( $\left.\sigma_{\text {pristine}}\right)$, Equation (1):

$\eta=\frac{\sigma_{\text {healed }}}{\sigma_{\text {pristine }}} \cdot 100$
The healing process of metal-ligand crosslinked elastomer was shown in Figure 3.

\subsubsection{Differential scanning calorimetry (DSC)}

Differential scanning calorimetry studies were performed using the DSC 204F1, NETZSCH (Germany) instrument. About 8 to $10 \mathrm{mg}$ of sample was weighed and placed inside the DSC aluminum pan, and in the temperature range of $-100^{\circ} \mathrm{C}$ to room temperature, at the heating rate was $10^{\circ} \mathrm{C} / \mathrm{min}$ under the liquid nitrogen atmosphere.

\subsubsection{Scanning electron microscopy (SEM)}

The morphologies of all samples were examined using a Field Emission Scanning Electron 348 Merlin Microscope (Germany). All the samples were cryo-fractured using the liquid nitrogen, and then the fractured surfaces were probed. Prior to the SEM test, the surface of all samples was sputtered with gold to provide improved conductivity.

\subsubsection{Atomic force microscopy (AFM)}

The depth profilometry of cut and healed surfaces were compared using AC-AFM Agilent 5500 Scanning Probe Microscope (USA) under tapping mode. The cantilever frequency was $150 \mathrm{kHz}$, and the force constant was $42 \mathrm{~N} / \mathrm{m}$.

\subsubsection{Optical microscopy}

The optical microscope (ZEISS Scope.A1 AX10) was deployed for surface damage-control analysis through the course of the healing process.

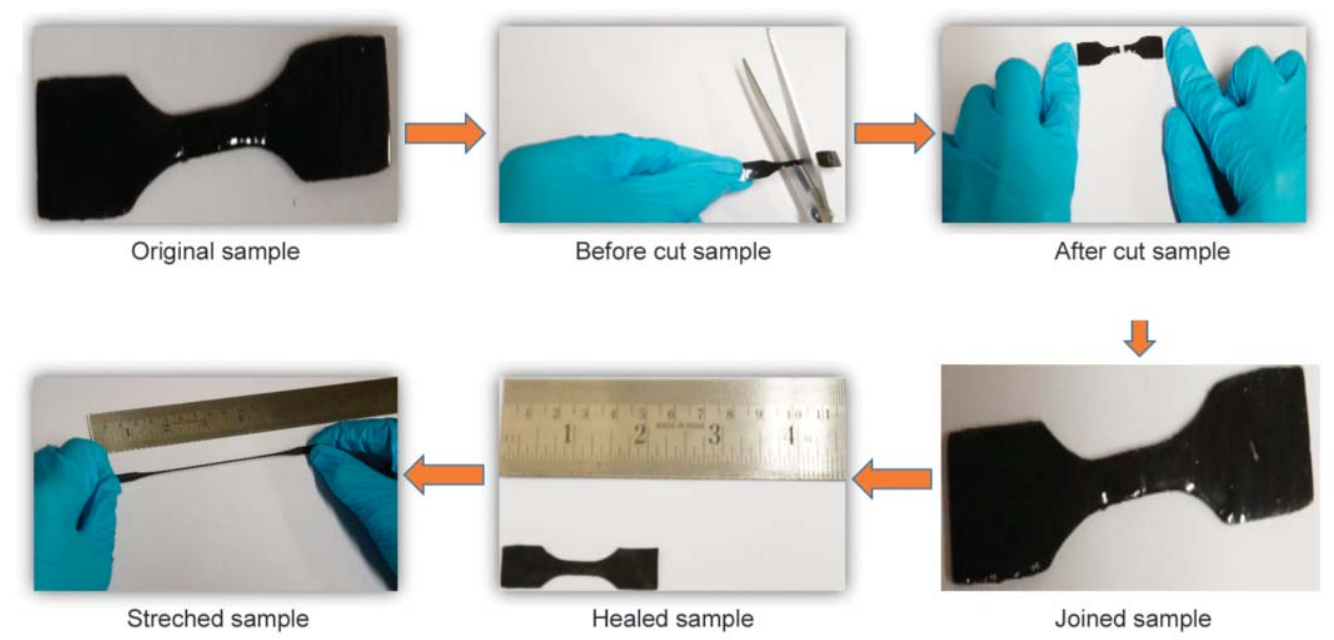

Figure 3. The healing process of the multiple metal-ligand crosslinked elastomers. 


\subsubsection{Rubber process analyzer (RPA 2000)}

Stress relaxation analysis of all samples was carried out using the rubber process analyzer (RPA 2000, Alpha Technologies, USA). Approximately $5 \mathrm{~g}$ of sample was subjected to a $3^{\circ}$ angular strain, while the temperature of upper and lower platens was maintained at $170{ }^{\circ} \mathrm{C}$ temperature. The decay in the modulus was monitored over a period of $12 \mathrm{~min}$.

\subsubsection{Tension set}

The tension set experiment of all samples was performed using a Universal Testing Machine (Hounsfield $\mathrm{H} 25 \mathrm{KS}$ ) apparatus, and the dumbbell specimens were enlarged (stress at $100 \% \mathrm{MPa}$ ) in the tensile direction at an extension rate of $50 \mathrm{~mm} / \mathrm{min}$ and keep at that position for 10 minutes at room temperature. It was then relaxed back to unstressed condition, and the percentage change in dimension in tensile direction was measured after 20 minutes and reported as tension set (Equation (2)):

Tension set $[\%]=\frac{\text { Change in length }}{\text { Original length }} \cdot 100$

\subsubsection{Swelling experiments}

The swelling experiment of all the rubber compounds was studied using a toluene solvent (molar volume $107 \mathrm{~cm}^{-3} / \mathrm{g}$ ). The sample was cut into a round size and then swollen in a toluene (reagent grade purity) solvent with the idea of the polymer-solvent interaction parameter. Preweighted rubber samples are swollen for $72 \mathrm{~h}$ at room temperature. After swelling $(72 \mathrm{~h})$, the solvent is dry quickly from the surface of the rubber specimen by a clean tissue paper, and then final weights were taken. The cross-link density, $v_{\mathrm{e}}$ $\left[\mathrm{cm}^{-3}\right]$ was got by using Equation (3):

$v_{\mathrm{e}}=\frac{\rho_{\mathrm{p}} N_{\mathrm{A}}}{M_{\mathrm{c}}}$

where $\rho_{\mathrm{p}}$ is the polymer density, $N_{\mathrm{A}}$ is the Avogadro's number, and $M_{\mathrm{c}}$ is the average molecular weight of the chain during cross-links. In a swelling study, the Flory equation (Equation (4)) is widely used to determine the $M_{\mathrm{c}}$ value:

$$
M_{\mathrm{c}}=-V_{\mathrm{s}} \rho_{\mathrm{p}} \frac{\phi_{\mathrm{p}}^{1 / 3}-0.5 \phi_{\mathrm{p}}}{\ln \left(1-\phi_{\mathrm{p}}\right)+\phi_{\mathrm{p}}+\chi \phi_{\mathrm{p}}^{2}}
$$

where $M_{\mathrm{c}}$ is the average molecular weight of the polymer chain between cross-links, $V_{\mathrm{s}}$ is the solvent molar volume, $\phi_{\mathrm{p}}$ is the polymer volume fraction in the swollen specimen, and $\chi$ is the polymer-solvent interaction parameter [38]. The value of $\chi$ is taken as 0.34 .

\subsubsection{Moving die rheometer (MDR) study}

The rheometric characteristics of all the samples were studied using moving die rheometer (MDR), Mansanto MDR-2000 (USA) at temperature $170^{\circ} \mathrm{C}$ for $30 \mathrm{~min}$. The experiments were carried out at $70 \mathrm{psi}$ die pressure, $1.7 \mathrm{~Hz}$ (100 CPM) frequency, and an oscillatory rotation amplitude of $0.5^{\circ}$ arc.

\subsubsection{High-resolution transmission electron microscope (HR-TEM) study}

The morphologies of all the rubber compounds were examined using a JEM-2100 HR-TEM, Make-JEOL, Japan, point to point resolution $(0.194 \mathrm{~nm})$ and $200 \mathrm{kV}$ electron beam accelerating voltage. The samples were prepared using the ultramicrotome cutting instrument.

\section{Results and discussion}

\subsection{Incorporation of DAP ligand and metal ion into XNBR}

The successful formation of amide linkage between the $-\mathrm{COOH}$ group of $\mathrm{XNBR}$ and the $-\mathrm{NH}_{2}$ group of DAP ligand and formation of coordination complexes of DAP ligand with various metal ions was confirmed by FTIR analysis. The FTIR spectra of XNBR, DAP ligand, DAP modified XNBR compound was discussed in Section 2.3.1 and various coordination cross-linked rubber samples (with $\mathrm{Co}^{2+}, \mathrm{Ni}^{2+}$, and $\mathrm{Zn}^{2+}$ ) were shown in Figure 4. After introducing various metal salts into the DAP modified rubber, several characteristic peaks were observed that confirm the successful formation of the coordination complex. Upon complexation with $\mathrm{Co}^{2+}$, the peak ascribed to $\mathrm{C}=\mathrm{N}$ bending vibration of DAP ligand shifted from 1453 to $1438 \mathrm{~cm}^{-1}$ and the $\mathrm{C}-\mathrm{N}$ stretching vibration of ligand shifted from 1301 to $1339 \mathrm{~cm}^{-1}$, because of the coordination bonding between pyridine part of the DAP ligand and $\mathrm{Co}^{2+}$ metal ion. The peaks at $1693 \mathrm{~cm}-1$ (amide band I) and $1618 \mathrm{~cm}^{-1}$ (amide band II) of amide linkage DAP shifted to 1678 and $1655 \mathrm{~cm}^{-1}$ after complexation with $\mathrm{Co}^{2+}$ metal ion, indicating the complexation of $\mathrm{Co}^{2+}$ ion through oxygen and nitrogen atoms of the amide group, and also the $-\mathrm{NH}$ asymmetric, 


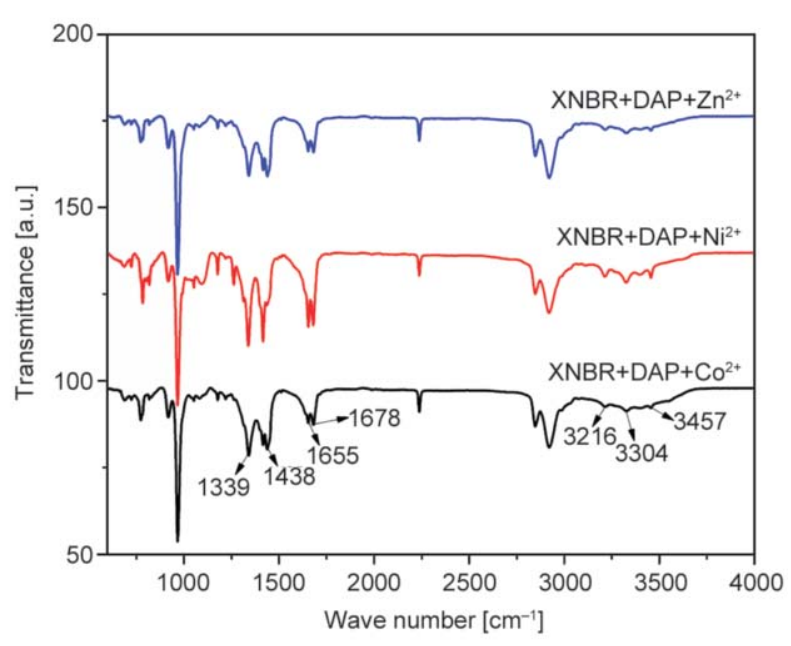

Figure 4. FTIR spectra of various metal-ligand modified rubber compounds.

symmetric and $\mathrm{N}+-\mathrm{H}$ stretching vibrations were observed, similar developments were observed the case of $\mathrm{Ni}$ and $\mathrm{Zn}$ salt-based rubber composites; the $\mathrm{C}=\mathrm{N}$ vibrations peak at $1453 \mathrm{~cm}^{-1}$ is shifted to $1438 \mathrm{~cm}^{-1}$ and the $\mathrm{C}-\mathrm{N}$ stretching vibration of ligand shifted from 1301 to $1339 \mathrm{~cm}^{-1}$ upon complexation with $\mathrm{Ni}^{2+}$ and $\mathrm{Zn}^{2+}$ metal ions. The amide band I and amide band II are shifted from 1693 and $1618 \mathrm{~cm}^{-1}$ to 1678 and $1655 \mathrm{~cm}^{-1}$, respectively after complexation with metal ions. The FT-IR results were strong evidence that the formation of amide linkage between $\mathrm{COOH}$ groups of XNBR rubber and the $\mathrm{NH}_{2}$ groups of DAP ligand (Figure 2), after addition of various metal ions on $\mathrm{XNBR}+\mathrm{DAP}$ system, metal-ligand coordination bond was formed (Figure 4). This metal-ligand coordination bond was dynamic and reversible in nature because after cut the sample, the coordination bond broke down and then reformed at a certain temperature and time (Figure 9).

\subsection{Mechanical properties of metal-ligand modified rubber composites}

The mechanical properties of various rubber compounds are summarized in Table 2. The XNBRDAP- $\mathrm{Co}^{2+}$ compound was shown the highest tensile strength up to $10.3 \mathrm{MPa}$ compared to Ni and $\mathrm{Zn}$ salt compounds, due to sufficient metal-ligand crosslinked into rubber network and electronic configuration of the metal ion. XNBR+DAP sample was exhibited the highest elongation at break, highest tension set, and lowest tensile strength due to the absence of metal ions that do not form any crosslinking network with the DAP ligand. The tensile strength of the uncured XNBR sample is around $0.5 \mathrm{MPa}$.

\section{Mechanical properties of XNBR with various metal ions modified rubber composites}

We have studied the mechanical properties of XNBR rubber with various metal-ligand modified compounds, and the XNBR rubber with only various metal ions compound are summarized in Table 2 and Table 3 . The result shows that the mechanical properties depend on the types of metal ions used in the system.

\subsection{Differential scanning calorimetric (DSC) study}

A differential scanning calorimetry study to finding the glass transition temperature of the metal-ligand cross-linked samples is shown in Figure 5 and the data in Table 4. The DSC glass transition temperature of virgin XNBR is $-25.2^{\circ} \mathrm{C}$ and, after treatment with DAP ligand is a shift to the $-23.3^{\circ} \mathrm{C}$ and then after treatment with the various metal ions, the glass transition temperature is increased, because of the metal ion is cross-linked with the DAP ligand into the XNBR chain. The XNBR-DAP/ $/ \mathrm{Co}^{2+}$ sample, the glass transition temperature is $-15.6^{\circ} \mathrm{C}, \mathrm{XNBR}-\mathrm{DAP} /$ $\mathrm{Ni}^{2+}$ sample is $-14.7^{\circ} \mathrm{C}$ and, the XNBR-DAP/ $/ \mathrm{Zn}^{2+}$ sample is $-18.6^{\circ} \mathrm{C}$ due to the Ni-DAP bond is

Table 3. The mechanical properties of XNBR with various metal ions modified rubber compounds.

\begin{tabular}{|l|c|c|c|c|}
\hline $\begin{array}{c}\text { Sample } \\
\text { mame }\end{array}$ & $\begin{array}{c}\boldsymbol{T} . \boldsymbol{S} \\
{[\mathbf{M P a}]}\end{array}$ & $\begin{array}{c}\boldsymbol{E B} \\
{[\%]}\end{array}$ & $\begin{array}{c}\mathbf{3 0 0 \%} \text { modulus } \\
{[\mathbf{M P a}]}\end{array}$ & $\begin{array}{c}\text { Hardness } \\
\text { [Shore A] }\end{array}$ \\
\hline $\mathrm{XNBR}+\mathrm{Co}^{2+}$ & $8.4 \pm 0.8$ & 1456 & 1.5 & $54 \pm 2$ \\
\hline $\mathrm{XNBR}+\mathrm{Ni}^{2+}$ & $6.8 \pm 0.5$ & 1344 & 1.8 & $55 \pm 2$ \\
\hline $\mathrm{XNBR}+\mathrm{Zn}^{2+}$ & $3.7 \pm 0.4$ & 1005 & 1.2 & $48 \pm 2$ \\
\hline
\end{tabular}

Table 2. The mechanical properties of various rubber compounds.

\begin{tabular}{|l|c|c|c|c|c|}
\hline \multicolumn{1}{|c|}{ Sample name } & $\begin{array}{c}\boldsymbol{T . S} \\
{[\mathbf{M P a}]}\end{array}$ & $\begin{array}{c}\boldsymbol{E B} \\
{[\mathbf{\%}]}\end{array}$ & $\begin{array}{c}\mathbf{3 0 0 \%} \text { modulus } \\
{[\mathbf{M P a}]}\end{array}$ & $\begin{array}{c}\text { Hardness } \\
{[\text { Shore A] }}\end{array}$ & $\begin{array}{c}\text { Tension set } \\
{[\%]}\end{array}$ \\
\hline $\mathrm{XNBR}+\mathrm{DAP}$ & 0.7 & $>2000$ & 0.3 & $40 \pm 1$ & $70 \pm 2$ \\
\hline $\mathrm{XNBR}+\mathrm{DAP}+\mathrm{Co}^{2+}$ & $10.3 \pm 1.1$ & 1436 & 2.1 & $60 \pm 2$ & $33 \pm 2$ \\
\hline $\mathrm{XNBR}+\mathrm{DAP}+\mathrm{Ni}^{2+}$ & $8.6 \pm 0.9$ & 1450 & 1.6 & $59 \pm 1$ & $17 \pm 2$ \\
\hline $\mathrm{XNBR}+\mathrm{DAP}+\mathrm{Zn}^{2+}$ & $4.3 \pm 0.6$ & 1560 & 0.8 & $52 \pm 1$ & $45 \pm 2$ \\
\hline
\end{tabular}




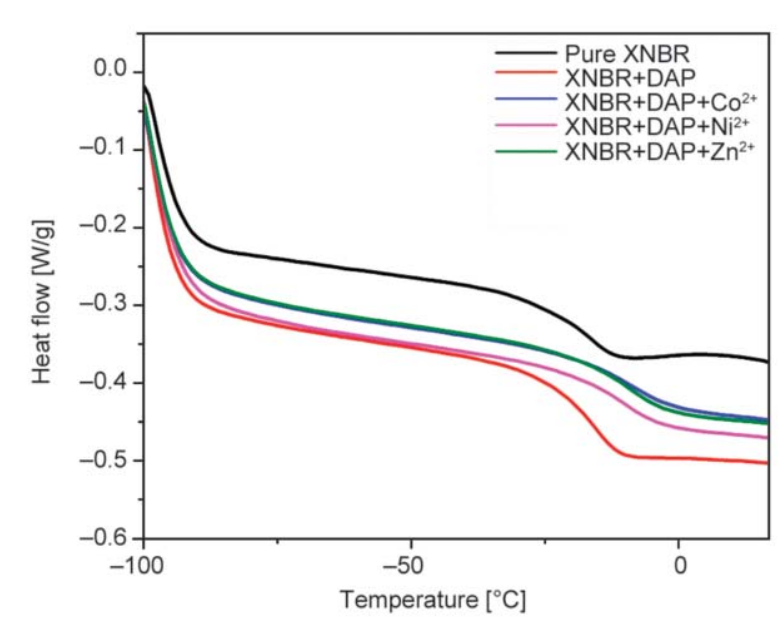

Figure 5. The differential scanning calorimetry (DSC) study of pristine XNBR, XNBR+DAP, XNBR-DAP/ $\mathrm{Co}^{2+}$, $\mathrm{XNBR}-\mathrm{DAP} / \mathrm{Ni}^{2+}$, and the XNBR-DAP/ $/ \mathrm{Zn}^{2+}$ samples.

stronger than the Co-DAP bond and the Zn-DAP bond, the Zn-DAP bond is more dynamic as compared to the $\mathrm{Co}$ and $\mathrm{Ni}$ metal ions.

Because of the electronic configuration of metal ions, in the case of $\mathrm{Zn}$ metal ion, the electronic configuration is $3 \mathrm{~d}^{10} 4 \mathrm{~S}^{2}$, $\mathrm{d}$-orbitals are completely fillup, so ligands are not able to attach with the non-bonded electron of $d$-orbitals. In this case, the ligands are loosely attached to an outer shell of the metal ions. Whereas $\mathrm{Co}$ and $\mathrm{Ni}$ the electronic configurations are $3 d^{7}$ and $3 d^{8}$, so ligands are able to attach with the non-bonded electron of $d$-orbitals, that's why ZnDAP bonds are more dynamic in nature as compared to Co-DAP and Ni-DAP bonds. So, in the case of $\mathrm{XNBR}-\mathrm{DAP} / \mathrm{Ni}^{2+}$ sample, the metal-ligand crosslinked density is higher, and the glass transition temperature is also higher as compared to the XNBR$\mathrm{DAP} / \mathrm{Co}^{2+}$ and the XNBR-DAP/ $\mathrm{Zn}^{2+}$ sample.

\subsection{Rubber process analyzer (RPA 2000).}

Stress-relaxation analysis was carried out at typical rubber processing temperature, i.e., $170^{\circ} \mathrm{C}$ by using

Table 4. The glass transition temperature $\left(T_{\mathrm{g}}\right)$ of various rubber compounds.

\begin{tabular}{|l|c|}
\hline \multicolumn{1}{|c|}{ Sample name } & $\begin{array}{c}\text { Glass transition temperature, } \boldsymbol{T}_{\mathbf{g}} \\
{\left[{ }^{\circ} \mathbf{C}\right]}\end{array}$ \\
\hline $\mathrm{XNBR}$ & -25.2 \\
\hline $\mathrm{XNBR}+\mathrm{DAP}$ & -23.3 \\
\hline $\mathrm{XNBR}+\mathrm{DAP}+\mathrm{Co}^{2+}$ & -15.6 \\
\hline $\mathrm{XNBR}+\mathrm{DAP}+\mathrm{Ni}^{2+}$ & -14.7 \\
\hline $\mathrm{XNBR}+\mathrm{DAP}+\mathrm{Zn}^{2+}$ & -18.6 \\
\hline
\end{tabular}

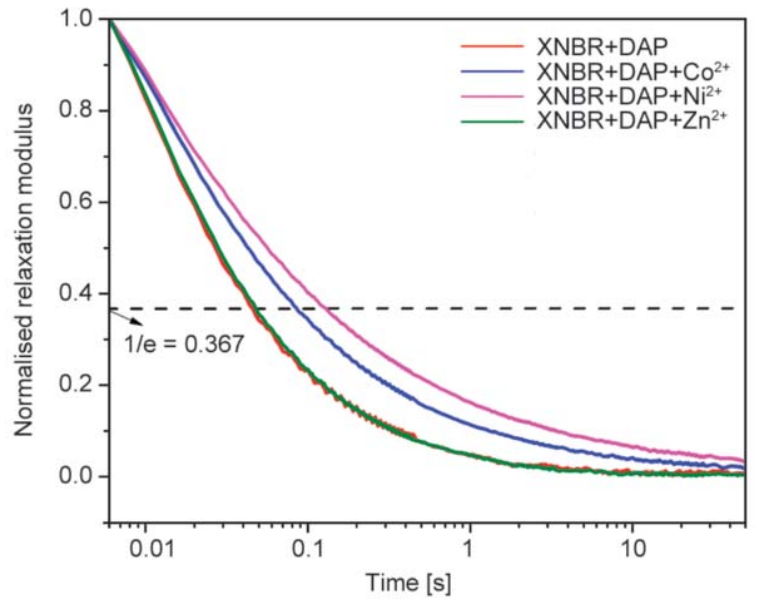

Figure 6. The stress-relaxation study of the $\mathrm{XNBR}+\mathrm{DAP}$, $\mathrm{XNBR}+\mathrm{DAP}+\mathrm{Co}^{2+}, \quad \mathrm{XNBR}+\mathrm{DAP}+\mathrm{Ni}^{2+}$, and $\mathrm{XNBR}+\mathrm{DAP}+\mathrm{Zn}^{2+}$ samples.

the rubber process analyzer, which is shown in Figure 6, and the data in Table 5. According to the Maxwell model (Equation (5)), where $\sigma_{0}$ is the original stress required to bring about the deformation and the $\sigma$ is the stress at a time $t$ after the material stays under the constant deformation and the $t_{\text {rel }}$ $(=\eta / G)$ is the relaxation time, $\eta$ and $G$ are the viscosity and the modulus of the materials. The $t_{\text {rel }}$ indicates the time taken for the stress to fall to a value $1 / \mathrm{e}$ times, which is $1 / 2.7=0.367$ or 0.37 times $\sigma_{0}$. The relaxation time of $\mathrm{XNBR}+\mathrm{DAP}+\mathrm{Ni}^{2+}$ sample is higher than $\mathrm{XNBR}+\mathrm{DAP}+\mathrm{Co}^{2+}$, and $\mathrm{XNBR}+\mathrm{DAP}+\mathrm{Zn}^{2+}$ samples, which suggest higher metal-ligand cross-linked network formation and the Ni-DAP bond is not so dynamic in nature, which results in the lower self-healing performance. But the $\mathrm{XNBR}+\mathrm{DAP}+\mathrm{Co}^{2+}$ sample, the relaxation time is quite higher than the $\mathrm{XNBR}+\mathrm{DAP}+\mathrm{Zn}^{2+}$ sample, in both cases, the Co-DAP bonds and the Zn-DAP bonds are dynamic in nature and the advantage to the higher heat-induced self-healing ability.

The Zn-DAP bonds are formed a weak coordination bond (shown in Figure 1) due to the electronic configuration of $\mathrm{Zn}$ metal ion $\left(3 \mathrm{~d}^{10} 4 \mathrm{~S}^{2}\right)$ and, as discussed in detail Section 3.3. The relaxation time of $\mathrm{XNBR}+\mathrm{DAP}$ sample is very lower, because in the absence of metal ions, having no crosslinking site, so do not exhibit self-healing behavior.

The stress relaxation in RPA and the glass transition temperature in DSC study are clear evidence that the $\mathrm{XNBR}+\mathrm{DAP}+\mathrm{Ni}^{2+}$ specimen has the highest relaxation time and highest glass transition temperature due to the highest metal-ligand crosslinked density 
Table 5. The normalized relaxation modulus corresponding with the relaxation time of the metal-ligand modified XNBR elastomer.

\begin{tabular}{|l|c|c|}
\hline \multicolumn{1}{|c|}{ Sample mame } & $\begin{array}{c}\text { Normalized } \\
\text { relaxation modulus }\end{array}$ & $\begin{array}{c}\text { Relaxation time } \\
{[\mathbf{s}]}\end{array}$ \\
\hline $\mathrm{XNBR}+\mathrm{DAP}$ & 0.367 & 0.043 \\
\hline $\mathrm{XNBR}+\mathrm{DAP}+\mathrm{Co}^{2+}$ & 0.367 & 0.084 \\
\hline $\mathrm{XNBR}+\mathrm{DAP}+\mathrm{Ni}^{2+}$ & 0.367 & 0.128 \\
\hline $\mathrm{XNBR}+\mathrm{DAP}+\mathrm{Zn}^{2+}$ & 0.367 & 0.048 \\
\hline
\end{tabular}

and strong metal-ligand coordination bond formation than the $\mathrm{Co}$ and $\mathrm{Zn}$ samples.

The room temperature tensile strength of $\mathrm{XNBR}+\mathrm{DAP}+\mathrm{Zn}^{2+}$ (Table 2) compound is much higher than the XNBR+DAP (without metal ion) sample but relaxation time (Equation (5)) at $170^{\circ} \mathrm{C}$ of $\mathrm{XNBR}+\mathrm{DAP}+\mathrm{Zn}^{2+}$ is quite higher than the $\mathrm{XNBR}+\mathrm{DAP}$ compound due to polymer/ligand or ligand/ metal ion reaction occurred at elevated temperature:

$$
\sigma=\sigma_{0} \cdot e^{-\frac{t}{t_{\text {rel }}}}
$$

\subsection{Self-healing and mechanical properties of the multiple metal-ligand modified XNBR \\ 3.5.1. The effect of temperature on healing performance and mechanical properties}

The carboxylated nitrile rubber (XNBR) was crosslinked by coordination complexes of various metal salt and DAP ligand. The corresponding elastomers (XNBR-DAP/ $/ \mathrm{Co}^{2+}, \mathrm{XNBR}-\mathrm{DAP} / \mathrm{Ni}^{2+}$, and $\mathrm{XNBR}-$ $\mathrm{DAP} / \mathrm{Zn}^{2+}$ ) were obtained after the compression molding. The mechanical properties and healing performances are tabulated in Table 6 . The XNBRDAP ligand (Reference sample), which is not healed (Figure 15), because of the absence of metal ion, does not form any metal-ligand coordination bond. The mechanical properties of Co-based compounds show higher value with respect to other metal moieties like $\mathrm{Ni}$ and $\mathrm{Zn}$ metal ions due to the different electronic configurations and complex formation. The electronic configuration of Co metal is $3 \mathrm{~d}^{7} 4 \mathrm{~S}^{2}$, $d$-orbital have more vacant site (free electron), the ligand can easily attach with metal ion and formed a stable coordination complex. Whereas Ni metal ion, the electronic configuration is $3 \mathrm{~d}^{8} 4 \mathrm{~S}^{2}, d$-orbital has the less vacant site (free electron), the ligand can attach with the free electron of $d$-orbital and also an outer shell of this metal ions, can form a strong metalligand coordination bond. In the case of $\mathrm{Zn}$ metal ion, an electronic configuration is $3 \mathrm{~d}^{10} 4 \mathrm{~S}^{2}, d$-orbital has no vacant site, so ligand can loosely attach with the outer shell of the metal ion. That's why the Cobased complex showed better mechanical properties compared to $\mathrm{Ni}$ and $\mathrm{Zn}$ metal ions.

The typical stress-strain plots of (XNBR-DAP/ $\mathrm{Co}^{2+}$, $\mathrm{XNBR}-\mathrm{DAP} / \mathrm{Ni}^{2+}$, and $\mathrm{XNBR}-\mathrm{DAP} / \mathrm{Zn}^{2+}$ ) are shown in Figure 7. It is obvious that the self-healing performance and mechanical performance of the healed sample can easily be changed by varying the temperature. The healing efficiency increases with increasing the temperature, as shown in Table 6. The modulus values of the healed sample increases with increasing the temperature due to polymer/ligand and ligand/metal ion interaction occurred at elevated temperature. The higher modulus can be a result of

Table 6. The mechanical and self-healing performance at various temperatures with a fixed time for 24 hrs.

\begin{tabular}{|c|c|c|c|c|c|c|}
\hline \multirow[t]{2}{*}{ Sample name } & \multirow{2}{*}{$\begin{array}{c}\text { Temperature } \\
{\left[{ }^{\circ} \mathrm{C}\right]}\end{array}$} & \multicolumn{2}{|c|}{$\begin{array}{c}\text { Tensile strength } \\
{[\mathrm{MPa}]}\end{array}$} & \multirow{2}{*}{$\begin{array}{c}300 \% \text { modulus of a } \\
\text { pristine sample } \\
\text { [MPa] }\end{array}$} & \multirow{2}{*}{$\begin{array}{c}300 \% \text { modulus of a } \\
\text { healed sample } \\
{[\mathrm{MPa}]}\end{array}$} & \multirow{2}{*}{$\begin{array}{c}\text { Self-healing } \\
\text { efficiency } \\
{[\%]}\end{array}$} \\
\hline & & Pristine sample & Healed sample & & & \\
\hline $\mathrm{XNBR}+\mathrm{DAP}+\mathrm{Co}^{2+}$ & \multirow{3}{*}{$\begin{array}{c}\text { Room } \\
\text { temperature }\end{array}$} & $10.3 \pm 1.1$ & $2.2 \pm 0.9$ & 2.1 & 1.8 & 21 \\
\hline $\mathrm{XNBR}+\mathrm{DAP}+\mathrm{Ni}^{2+}$ & & $8.6 \pm 0.9$ & $1.5 \pm 0.5$ & 1.6 & 1.4 & 17 \\
\hline $\mathrm{XNBR}+\mathrm{DAP}+\mathrm{Zn}^{2+}$ & & $4.3 \pm 0.6$ & $2.4 \pm 0.7$ & 0.8 & 0.9 & 55 \\
\hline $\mathrm{XNBR}+\mathrm{DAP}+\mathrm{Co}^{2+}$ & \multirow{3}{*}{40} & $10.3 \pm 1.1$ & $3.0 \pm 1.2$ & 2.1 & 2.0 & 29 \\
\hline $\mathrm{XNBR}+\mathrm{DAP}+\mathrm{Ni}^{2+}$ & & $8.6 \pm 0.9$ & $1.9 \pm 0.8$ & 1.6 & 1.4 & 22 \\
\hline $\mathrm{XNBR}+\mathrm{DAP}+\mathrm{Zn}^{2+}$ & & $4.3 \pm 0.6$ & $2.9 \pm 0.8$ & 0.8 & 1.1 & 66 \\
\hline $\mathrm{XNBR}+\mathrm{DAP}+\mathrm{Co}^{2+}$ & \multirow{3}{*}{60} & $10.3 \pm 1.1$ & $4.5 \pm 0.6$ & 2.1 & 1.7 & 44 \\
\hline $\mathrm{XNBR}+\mathrm{DAP}+\mathrm{Ni}^{2+}$ & & $8.6 \pm 0.9$ & $2.1 \pm 1.1$ & 1.6 & 2.1 & 24 \\
\hline $\mathrm{XNBR}+\mathrm{DAP}+\mathrm{Zn}^{2+}$ & & $4.3 \pm 0.6$ & $3.5 \pm 0.7$ & 0.8 & 0.9 & 79 \\
\hline $\mathrm{XNBR}+\mathrm{DAP}+\mathrm{Co}^{2+}$ & \multirow{3}{*}{80} & $10.3 \pm 1.1$ & $9.1 \pm 1.3$ & 2.1 & 2.4 & 88 \\
\hline $\mathrm{XNBR}+\mathrm{DAP}+\mathrm{Ni}^{2+}$ & & $8.6 \pm 0.9$ & $4.8 \pm 1.1$ & 1.6 & 2.3 & 56 \\
\hline $\mathrm{XNBR}+\mathrm{DAP}+\mathrm{Zn}^{2+}$ & & $4.3 \pm 0.6$ & $4.4 \pm 1.2$ & 0.8 & 1.3 & 100 \\
\hline
\end{tabular}



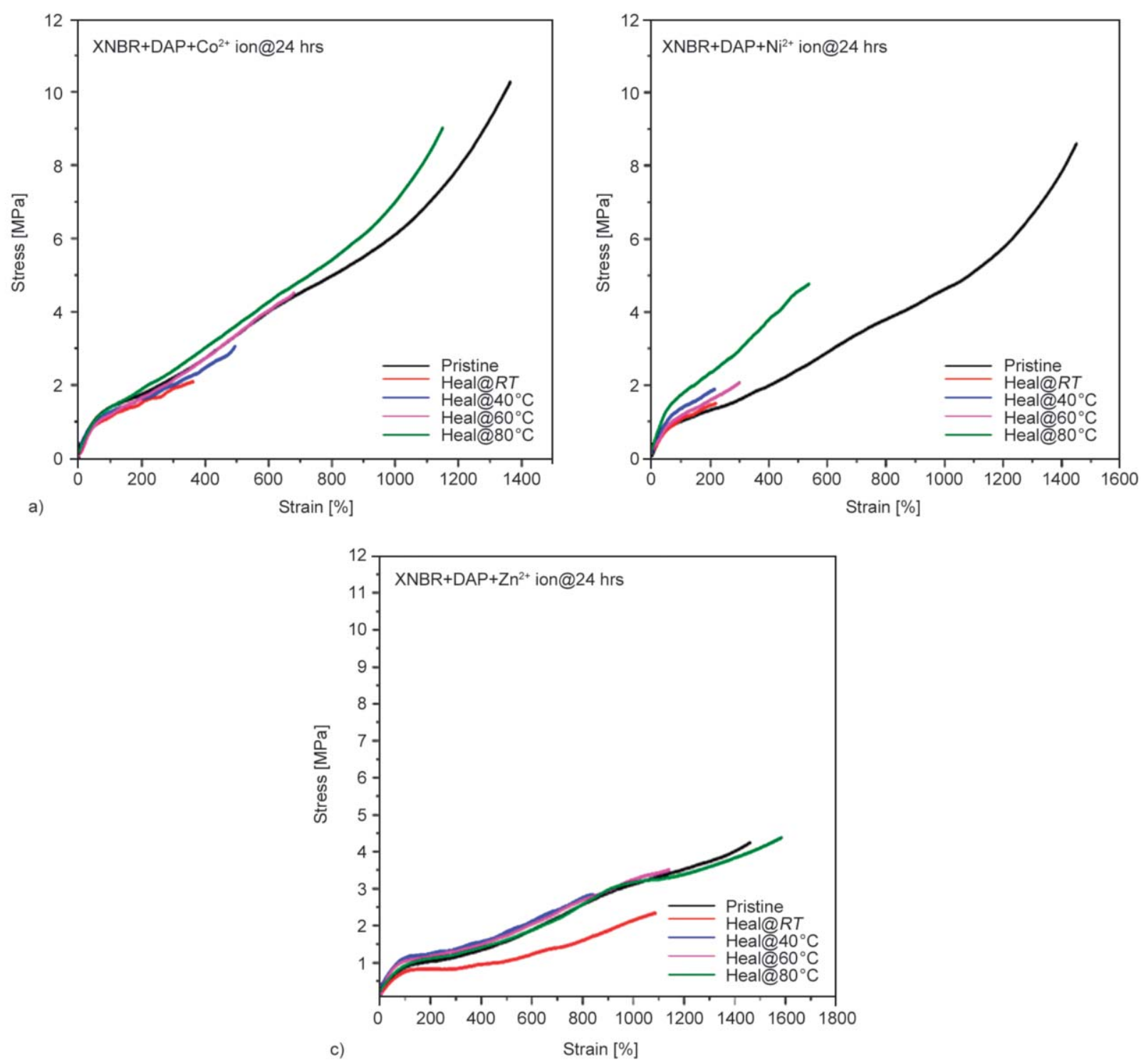

Figure 7. Typical stress-strain plots of virgin and healed samples at different temperatures; (a) $\mathrm{XNBR}+\mathrm{DAP}+\mathrm{Co}^{2+}$, (b) $\mathrm{XNBR}+\mathrm{DAP}+\mathrm{Ni}^{2+}$, and (c) $\mathrm{XNBR}+\mathrm{DAP}+\mathrm{Zn}^{2+}$.

higher mobility of macromolecules of the healed sample.

The tensile strength of $\mathrm{XNBR}-\mathrm{DAP} / \mathrm{Zn}^{2+}$ is $4.3 \pm 0.6$ $\mathrm{MPa}$, with a $300 \%$ modulus $\approx 0.8 \mathrm{MPa}$ for a virgin sample. The XNBR-DAP $/ \mathrm{Ni}^{2+}$ sample tensile strength reached $8.6 \pm 0.9 \mathrm{MPa}$ with a $300 \%$ modulus $\approx$ $1.6 \mathrm{MPa}$ and $\mathrm{XNBR}-\mathrm{DAP} / \mathrm{Co}^{2+}$ sample is $10.3 \pm 1.1 \mathrm{MPa}$ with a $300 \%$ modulus $\approx 2.1 \mathrm{MPa}$. The samples of XNBR-DAP/Co ${ }^{2+}$ and XNBR-DAP/Ni2 ${ }^{+}$ are harder than the XNBR-DAP/ $\mathrm{Zn}^{2+}$ sample because $\mathrm{Co}^{2+}$ and $\mathrm{Ni}^{2+}$ ions are formed a stronger bond with DAP ligand into the XNBR rubber than the $\mathrm{Zn}^{2+}$ ion. After that, the healing concert of all various metal-ligand crosslinked XNBR is established.
The specimens are cut into two pieces, then cut specimens are immediately touched together and lightly pressed to secure the good contact, keep it for $1 \mathrm{~min}$ at room temperature and then do self-healing test at various temperatures (room temperature, 40 , 60 , and $80^{\circ} \mathrm{C}$ ) for a fixed time $24 \mathrm{hrs}$ in a vacuum oven but not in vacuum condition. In the case of $\mathrm{XNBR}-\mathrm{DAP} / \mathrm{Zn}^{2+}$ sample, the self-healing efficiency increases with increasing the temperature. After $24 \mathrm{~h}$ of the room-temperature healing process, the healing efficiency was 55\% which increased up to $100 \%$ after the mending process carried out at $80^{\circ} \mathrm{C}$ temperature. Similarly, the healing efficiency of $\mathrm{XNBR}-\mathrm{DAP} / \mathrm{Co}^{2+}$ and $\mathrm{XNBR}-\mathrm{DAP} / \mathrm{Ni}^{2+}$ samples 
increases with increasing the temperature. The healing efficiency of XNBR-DAP/ $/ \mathrm{Co}^{2+}$ sample after $24 \mathrm{~h}$ of the mending process at room temperature and $80^{\circ} \mathrm{C}$ is 21 and $88 \%$, respectively. $\mathrm{Co}^{2+}$ ion and DAP ligand form a stronger bond as compared to the $\mathrm{Zn}^{2+}$ ion. In the case of XNBR-DAP/ $\mathrm{Ni}^{2+}$ sample, the healing efficiency after $24 \mathrm{~h}$ of the mending process is $17 \%$ (at room temperature) and $56 \%$ (at $80^{\circ} \mathrm{C}$ temperature); this is attributed to a more stronger coordination bond between the $\mathrm{Ni}^{2+}$ ion and the DAP ligand as compared to coordination bond that $\mathrm{Co}^{2+}$ and $\mathrm{Zn}^{2+}$ ions forms with DAP ligand in $\mathrm{XNBR}$ rubber. In the case of XNBR-DAP/ $/ \mathrm{Zn}^{2+}$ sample, after healing at $24 \mathrm{~h}$, the tensile strength of healed sample is higher $(4.4 \pm 1.2 \mathrm{MPa})$ than the pristine sample $(4.3 \pm 0.6 \mathrm{MPa})$, which could be explained through the extra metal-ligand coordination bond formation that occurs over time at elevated temperature and also maybe the thermo-oxidative aging of the sample when it is exposed in a vacuum oven at $80^{\circ} \mathrm{C}$ for 24 hours.

The Young's modulus and yielding stress (Figure 7) of the healed sample became much higher than the virgin sample because of polymer/ligand or ligand/ metal ion reaction occurred at elevated temperatures.

\subsubsection{The effect of healing time on mechanical properties and healing performance}

The effect of healing time on the mechanical and selfhealing performances of XNBR-DAP/ $/ \mathrm{Co}^{2+}, \mathrm{XNBR}-$ $\mathrm{DAP} / \mathrm{Ni}^{2+}$, and $\mathrm{XNBR}-\mathrm{DAP} / \mathrm{Zn}^{2+}$ samples was examined (Table 7), and the typical stress-strain graphs for various samples were plotted (Figure 8).

The results reveal that the self-healing efficiency of samples gradually improves over time. The flawless (uncut) XNBR-DAP $/ \mathrm{Zn}^{2+}$ sample exhibits $4.3 \mathrm{MPa}$ tensile strength, whereas the mended XNBR$\mathrm{DAP} / \mathrm{Zn}^{2+}$ sample exhibits gradual increment in the tensile strength through $1.6 ; 2.6 ; 2.9 ; 3.2 ; 3.6$; 4.4 MPa over $0.5 ; 1 ; 3 ; 6 ; 12$ and $24 \mathrm{~h}$ of healing process, respectively. The tensile strength is $4.4 \pm 1.2 \mathrm{MPa}$ and the healing efficiency is $100 \%$, and $\mathrm{XNBR}-\mathrm{DAP} / \mathrm{Co}^{2+}$ sample, the tensile strength, and healing efficiency are $9.1 \pm 1.3 \mathrm{MPa}$ and $88 \%$, the XNBR-DAP/Ni ${ }^{2+}$ sample, the tensile strength, and the healing efficiency are $4.8 \pm 1.1 \mathrm{MPa}$ and $56 \%$. The 24 hours self-healing time is contemplated to supreme and also energy-saving matter.

The recovery of strength and corresponding healing efficiencies through the mending period is shown in Figure 9. The healing results are proposed that the $\mathrm{Ni}^{2+}$-DAP bond is stronger than the $\mathrm{Co}^{2+}$-DAP and

Table 7. Summary of mechanical and self-healing properties at different times with a fixed $80^{\circ} \mathrm{C}$ temperature.

\begin{tabular}{|c|c|c|c|c|c|c|}
\hline \multirow[t]{2}{*}{ Sample name } & \multirow{2}{*}{$\begin{array}{l}\text { Time } \\
\text { [hrs] }\end{array}$} & \multicolumn{2}{|c|}{$\begin{array}{c}\text { Tensile strength } \\
\text { [MPa] }\end{array}$} & \multirow{2}{*}{$\begin{array}{c}300 \% \text { modulus of a } \\
\text { pristine sample } \\
\text { [MPa] }\end{array}$} & \multirow{2}{*}{$\begin{array}{c}\mathbf{3 0 0 \%} \text { modulus of a } \\
\text { healed sample } \\
{[\mathrm{MPa}]}\end{array}$} & \multirow{2}{*}{$\begin{array}{c}\text { Self-healing } \\
\text { efficiency } \\
{[\%]}\end{array}$} \\
\hline & & Pristine sample & Healed sample & & & \\
\hline $\mathrm{XNBR}+\mathrm{DAP}+\mathrm{Co}^{2+}$ & \multirow{3}{*}{0.5} & $10.3 \pm 1.1$ & $2.7 \pm 0.9$ & 2.1 & 1.9 & 26 \\
\hline $\mathrm{XNBR}+\mathrm{DAP}+\mathrm{Ni}^{2+}$ & & $8.6 \pm 0.9$ & $1.5 \pm 1.2$ & 1.6 & 1.4 & 17 \\
\hline $\mathrm{XNBR}+\mathrm{DAP}+\mathrm{Zn}^{2+}$ & & $4.3 \pm 0.6$ & $1.6 \pm 0.7$ & 0.8 & 0.8 & 37 \\
\hline $\mathrm{XNBR}+\mathrm{DAP}+\mathrm{Co}^{2+}$ & \multirow{3}{*}{1} & $10.3 \pm 1.1$ & $3.3 \pm 0.6$ & 2.1 & 1.9 & 32 \\
\hline $\mathrm{XNBR}+\mathrm{DAP}+\mathrm{Ni}^{2+}$ & & $8.6 \pm 0.9$ & $2.2 \pm 1.3$ & 1.6 & 1.6 & 26 \\
\hline $\mathrm{XNBR}+\mathrm{DAP}+\mathrm{Zn}^{2+}$ & & $4.3 \pm 0.6$ & $2.6 \pm 1.2$ & 0.8 & 1.2 & 59 \\
\hline $\mathrm{XNBR}+\mathrm{DAP}+\mathrm{Co}^{2+}$ & \multirow{3}{*}{3} & $10.3 \pm 1.1$ & $4.2 \pm 0.8$ & 2.1 & 2.2 & 41 \\
\hline $\mathrm{XNBR}+\mathrm{DAP}+\mathrm{Ni}^{2+}$ & & $8.6 \pm 0.9$ & $2.7 \pm 0.4$ & 1.6 & 3.0 & 31 \\
\hline $\mathrm{XNBR}+\mathrm{DAP}+\mathrm{Zn}^{2+}$ & & $4.3 \pm 0.6$ & $2.9 \pm 0.9$ & 0.8 & 1.3 & 66 \\
\hline $\mathrm{XNBR}+\mathrm{DAP}+\mathrm{Co}^{2+}$ & \multirow{3}{*}{6} & $10.3 \pm 1.1$ & $5.3 \pm 1.3$ & 2.1 & 2.3 & 52 \\
\hline $\mathrm{XNBR}+\mathrm{DAP}+\mathrm{Ni}^{2+}$ & & $8.6 \pm 0.9$ & $3.6 \pm 0.4$ & 1.6 & 1.6 & 42 \\
\hline $\mathrm{XNBR}+\mathrm{DAP}+\mathrm{Zn}^{2+}$ & & $4.3 \pm 0.6$ & $3.2 \pm 0.9$ & 0.8 & 1.1 & 73 \\
\hline $\mathrm{XNBR}+\mathrm{DAP}+\mathrm{Co}^{2+}$ & \multirow{3}{*}{12} & $10.3 \pm 1.1$ & $5.8 \pm 0.7$ & 2.1 & 2.5 & 57 \\
\hline $\mathrm{XNBR}+\mathrm{DAP}+\mathrm{Ni}^{2+}$ & & $8.6 \pm 0.9$ & $3.7 \pm 1.1$ & 1.6 & 2.8 & 43 \\
\hline $\mathrm{XNBR}+\mathrm{DAP}+\mathrm{Zn}^{2+}$ & & $4.3 \pm 0.6$ & $3.6 \pm 1.2$ & 0.8 & 1.3 & 82 \\
\hline $\mathrm{XNBR}+\mathrm{DAP}+\mathrm{Co}^{2+}$ & \multirow{3}{*}{24} & $10.3 \pm 1.1$ & $9.1 \pm 1.3$ & 2.1 & 2.4 & 88 \\
\hline $\mathrm{XNBR}+\mathrm{DAP}+\mathrm{Ni}^{2+}$ & & $8.6 \pm 0.9$ & $4.8 \pm 1.1$ & 1.6 & 2.3 & 56 \\
\hline $\mathrm{XNBR}+\mathrm{DAP}+\mathrm{Zn}^{2+}$ & & $4.3 \pm 0.6$ & $4.4 \pm 1.2$ & 0.8 & 1.3 & 100 \\
\hline
\end{tabular}



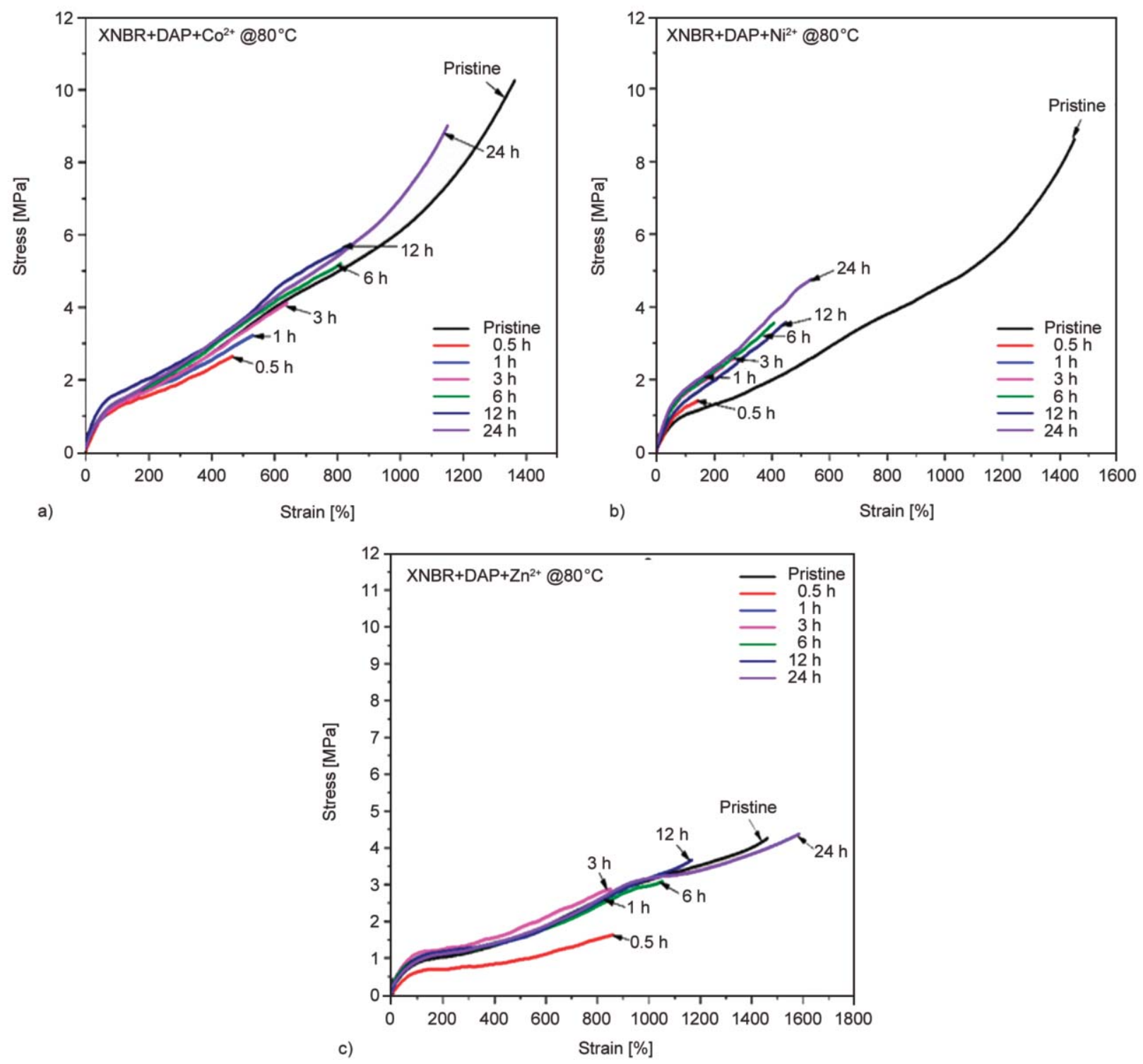

Figure 8. The typical stress-strain plots of both pristine and healed sample of (a) $\mathrm{XNBR}+\mathrm{DAP}+\mathrm{Co}^{2+}$, (b) $\mathrm{XNBR}+\mathrm{DAP}+\mathrm{Ni}^{2+}$, and (c) $\mathrm{XNBR}+\mathrm{DAP}+\mathrm{Zn}^{2+}$.

$\mathrm{Zn}^{2+}$-DAP bond and $\mathrm{Ni}^{2+}$-DAP bond is not so dynamic as like the $\mathrm{Co}^{2+}$-DAP and $\mathrm{Zn}^{2+}$-DAP bond.

\subsubsection{The different crosslinked systems on self- healing properties}

We tabulated the self-healing properties of different metal-ligand coordination system of XNBR-DAP/ $\mathrm{Co}^{2+}, \mathrm{XNBR}-\mathrm{DAP} / \mathrm{Ni}^{2+}$, and the XNBR-DAP $/ \mathrm{Zn}^{2+}$ systems are shown in Figure 10.

Although XNBR-DAP/ $/ \mathrm{Zn}^{2+}$ sample exhibits lower tensile strength, outstanding healing properties were observed, as the tensile strength $4.3 \pm 0.6 \mathrm{MPa}$ (virgin sample) and $100 \%$ healing was obtained due to weak $\mathrm{Zn}$-DAP bond and the insufficient metal-ligand crosslinking density form into the XNBR rubber. But in
XNBR-DAP $/ \mathrm{Co}^{2+}$ sample exhibits both fairly good healing properties $(88 \%)$ and very good mechanical strength $(10.3 \pm 1.1 \mathrm{Mpa})$, due to strong Co-DAP dynamic bond and the good metal-ligand crosslinking. Whereas, $\mathrm{XNBR}-\mathrm{DAP} / \mathrm{Ni}^{2+}$ sample exhibit $8.6 \pm 0.9 \mathrm{MPa}$ (medium) tensile strength and the $56 \%$ (lowest) healing efficiency, due to stronger Ni-DAP bond and sufficient metal-ligand crosslinking into the XNBR rubber.

\subsection{The FTIR analysis of metal-ligand modified compounds after self-healing at $80^{\circ} \mathrm{C}$ for 24 hours}

The FT-IR analysis has demonstrated the formation of a coordination bond between the DAP ligand and 

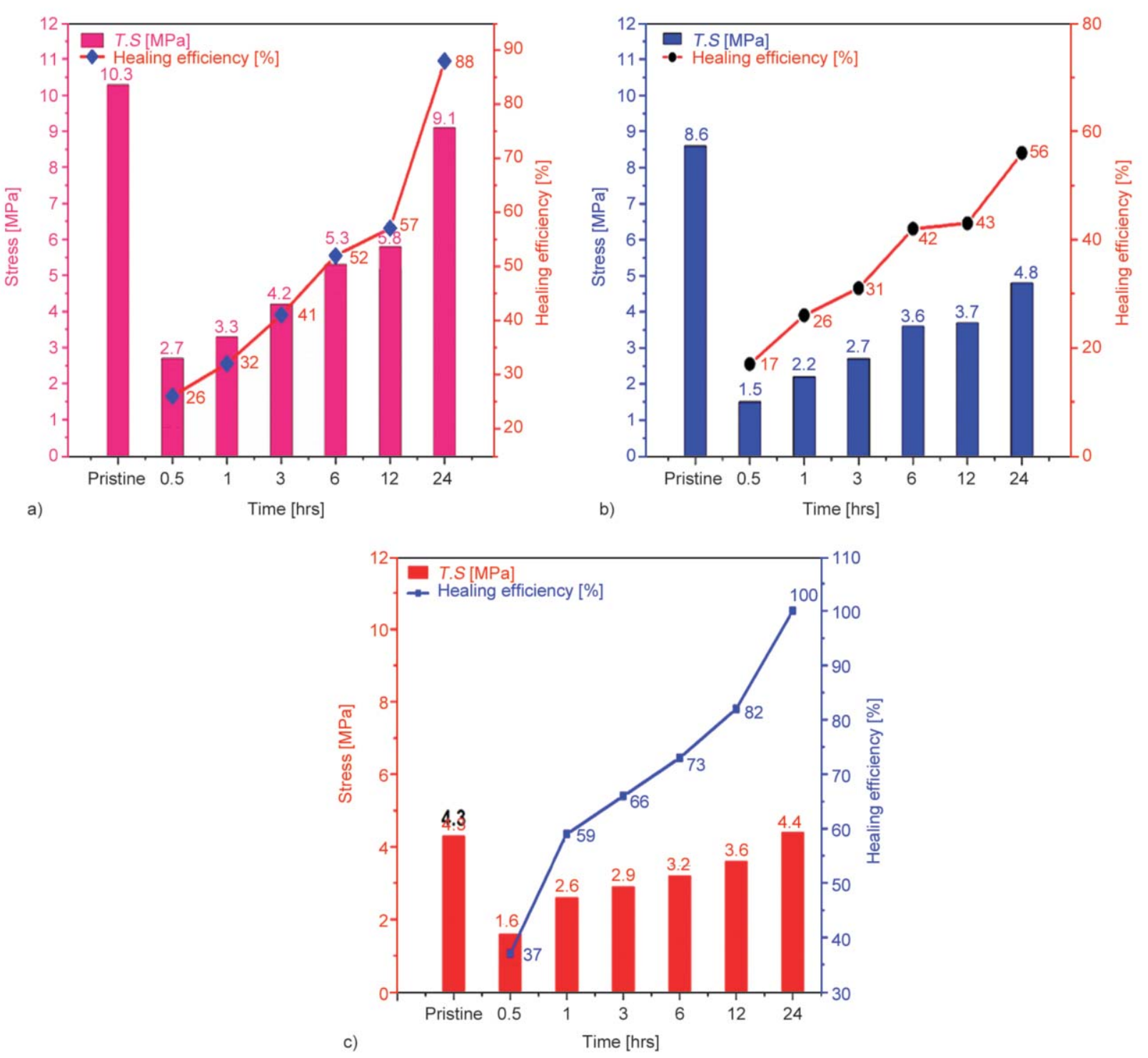

Figure 9. The self-healing properties of (a) $\mathrm{XNBR}+\mathrm{DAP}+\mathrm{Co}^{2+}$, (b) $\mathrm{XNBR}+\mathrm{DAP}+\mathrm{Ni}^{2+}$, and (c) $\mathrm{XNBR}+\mathrm{DAP}+\mathrm{Zn}^{2+}$ samples.

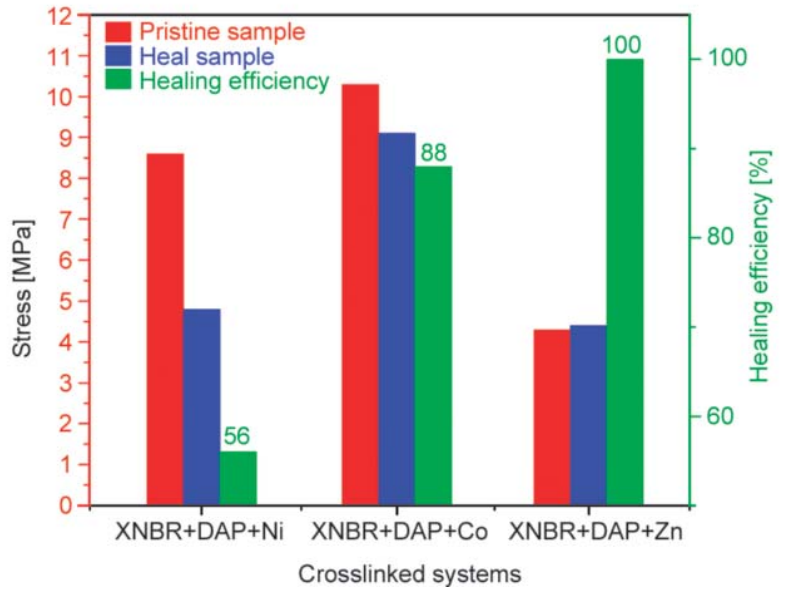

Figure 10. The self-healing properties with different crosslinked systems.

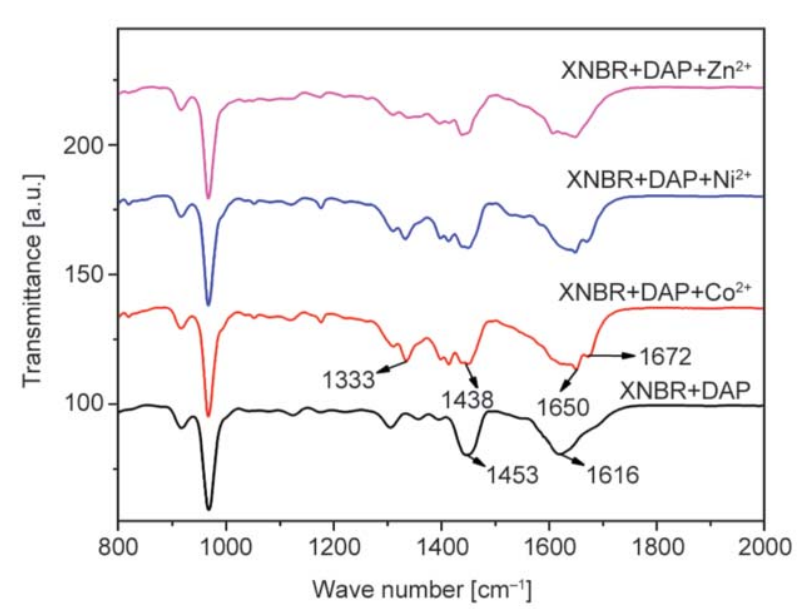

Figure 11. The FT-IR spectra of various metal-ligand modified compounds after self-healing. 
the various metal ion after self-healing at $80^{\circ} \mathrm{C}$ for 24 hours. FT-IR spectra of the control sample $(\mathrm{XNBR}+\mathrm{DAP})$ and healed sample $\left(\mathrm{XNBR}+\mathrm{DAP}+\mathrm{Co}^{2+}, \quad \mathrm{XNBR}+\mathrm{DAP}+\mathrm{Ni}^{2+}, \quad\right.$ and $\mathrm{XNBR}+\mathrm{DAP}+\mathrm{Zn}^{2+}$ ) were shown in Figure 11. In the case of XNBR+DAP compound, the characteristic peak at 16161 and $1453 \mathrm{~cm}^{-1}$ corresponds to the $\mathrm{N}-\mathrm{H}$ bending and the $\mathrm{C}=\mathrm{C}$ stretching vibration of free pyridine. The $\mathrm{XNBR}+\mathrm{DAP}+\mathrm{Co}^{2+}$ compound, the change of amide band I, and amide band II were recorded during the healing process. However, the amide band I was shifted to the lower wavenumber and the amide II was shifted to the higher wavenumber. In the case of $\mathrm{XNBR}+\mathrm{DAP}+\mathrm{Co}^{2+}$ compound, after $24 \mathrm{~h}$ self-healing at $80^{\circ} \mathrm{C}$, the amide band I ( $\mathrm{C}=\mathrm{O}$ stretching) and amide band II $(-\mathrm{N}-\mathrm{H}$ bending $)$ were recorded at 1650 and $1672 \mathrm{~cm}^{-1}$, with respect to that of the virgin sample. The peak at $1438 \mathrm{~cm}^{-1}$, $\mathrm{C}=\mathrm{N}$ stretching vibration of coordinated pyridine of the DAP ligand throughout the damage and healing process. The results showed that the various metal-ligand coordination bond was formed after self-healing. The healing ability was attributed to the dynamic bond between the $\mathrm{Co}^{2+}$ metal ion and the DAP ligand. Similarly, the dynamic behavior of $\mathrm{XNBR}+\mathrm{DAP}+\mathrm{Ni}^{2+}$ and $\mathrm{XNBR}+\mathrm{DAP}+\mathrm{Zn}^{2+}$ compounds were also happened and was shown in Figure 11.

\subsection{Mechanism of self-healing of XNBR created by the different metal-DAP bonds}

The healing mechanism of XNBR rubber is tabulated by the intrinsic dynamic supramolecular metalligand coordination bonds at the damaged point and which is shown in Figure 12. The XNBR-DAP/ $/ \mathrm{Co}^{2+}$, $\mathrm{XNBR}-\mathrm{DAP} / \mathrm{Ni}^{2+}$, and the XNBR-DAP/ $/ \mathrm{Zn}^{2+}$ are used as a proposed model elastomer to tabulated the chemistry at the crack region changes during the fracture-repair cycle. In the case of a damaged specimen of XNBR-DAP/ $/ \mathrm{Zn}^{2+}$ and XNBR-DAP/ $/ \mathrm{Co}^{2+}$, the $\mathrm{Zn}$-DAP bond is more weak and dynamic than the Co-DAP bond, because of, lower metal-ligand cross-linked density and rebonding after 24 hours at $80^{\circ} \mathrm{C}$ of the healed sample. But in the case of XNBR$\mathrm{DAP} / \mathrm{Ni}^{2+}$ specimen, the Ni-pyridine bond is more strong as compare to the $\mathrm{Co}$ and $\mathrm{Zn}$ metal, in fracture sample the Ni-pyridine bond is not broken down (as shown in Figure 12) but Ni-DAP bonds are broken down and these bonds are rebonding after 24 hours at $80^{\circ} \mathrm{C}$ of the healed sample.

\subsection{Rheometric (MDR) study of XNBR rubber with various metal ions compounds}

The rheometric analysis of all the rubber composites is shown in Figure 13. In the case of XNBR+DAP (without metal ion) compound, the storage modulus and loss modulus is almost similar, with no change

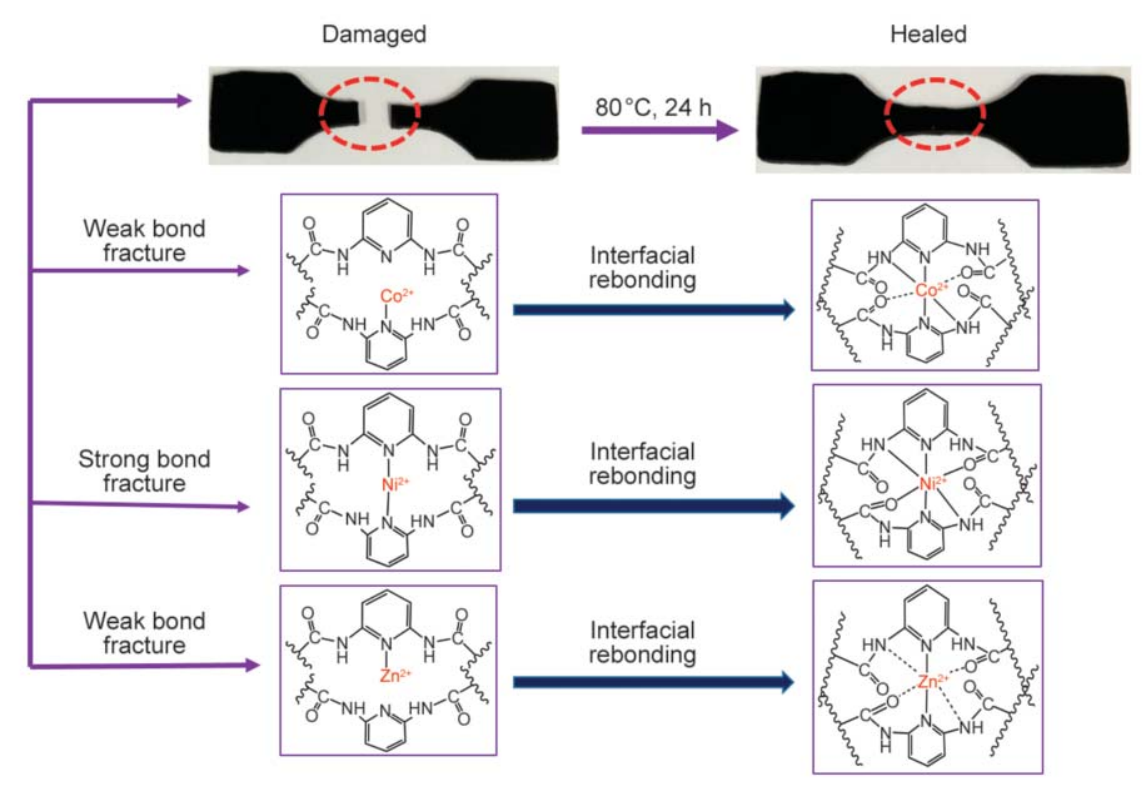

Figure 12. The schematic illustration of the scission and regeneration of the different metal-ligand bonds during self-healing. 

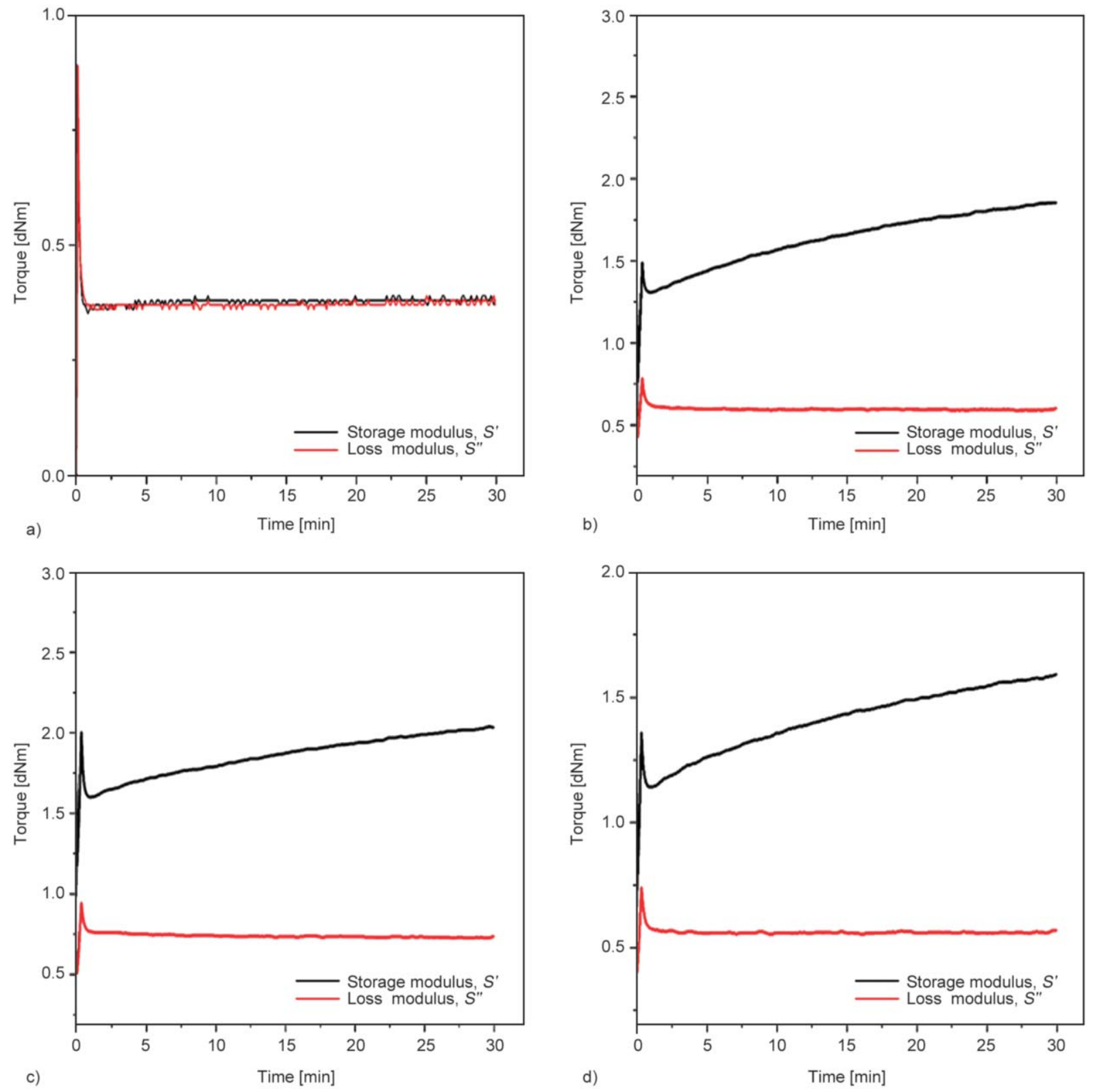

Figure 13. The MDR study of various rubber composites (a) $\mathrm{XNBR}+\mathrm{DAP}$ (without metal ion), (b) $\mathrm{XNBR}+\mathrm{Co}^{2+}$, (c) $\mathrm{XNBR}+\mathrm{Ni}^{2+}$, and (d) $\mathrm{XNBR}+\mathrm{Zn}^{2+}$ compounds with metal ions.

in modulus value due to the absence of metal ion no cross-linking takes place in the polymer chain. The DAP ligand can only form the amide bond between the $-\mathrm{COOH}$ group of XNBR rubber and the $-\mathrm{NH}_{2}$ group of DAP ligand and also confirmed in FT-IR analysis (Figure 2). Whereas XNBR rubber with various metal ions compounds, the storage modulus increases with time because of various metal ions and the $-\mathrm{COOH}$ group interaction takes place into a polymer matrix. So the metal-oxygen bonds in polymer chains are improved the mechanical as well as the rheometric properties.

\subsection{Swelling study}

The cross-link density of all the rubber composites is an analysis using swelling experiment techniques, which is shown in Figure 14. To compare the crosslink density of XNBR rubber cross-linked via various metal-ligand systems and the XNBR rubber with cross-linked only various metal ions, which is shown in Figure 14b. In the case of XNBR+DAP+Ni system, the cross-link density is very high compared to $\mathrm{Co}$ and $\mathrm{Zn}$ systems. Whereas various metal ions modified compounds are shows the less cross-linking density compared to metal-ligand rubber compounds, 

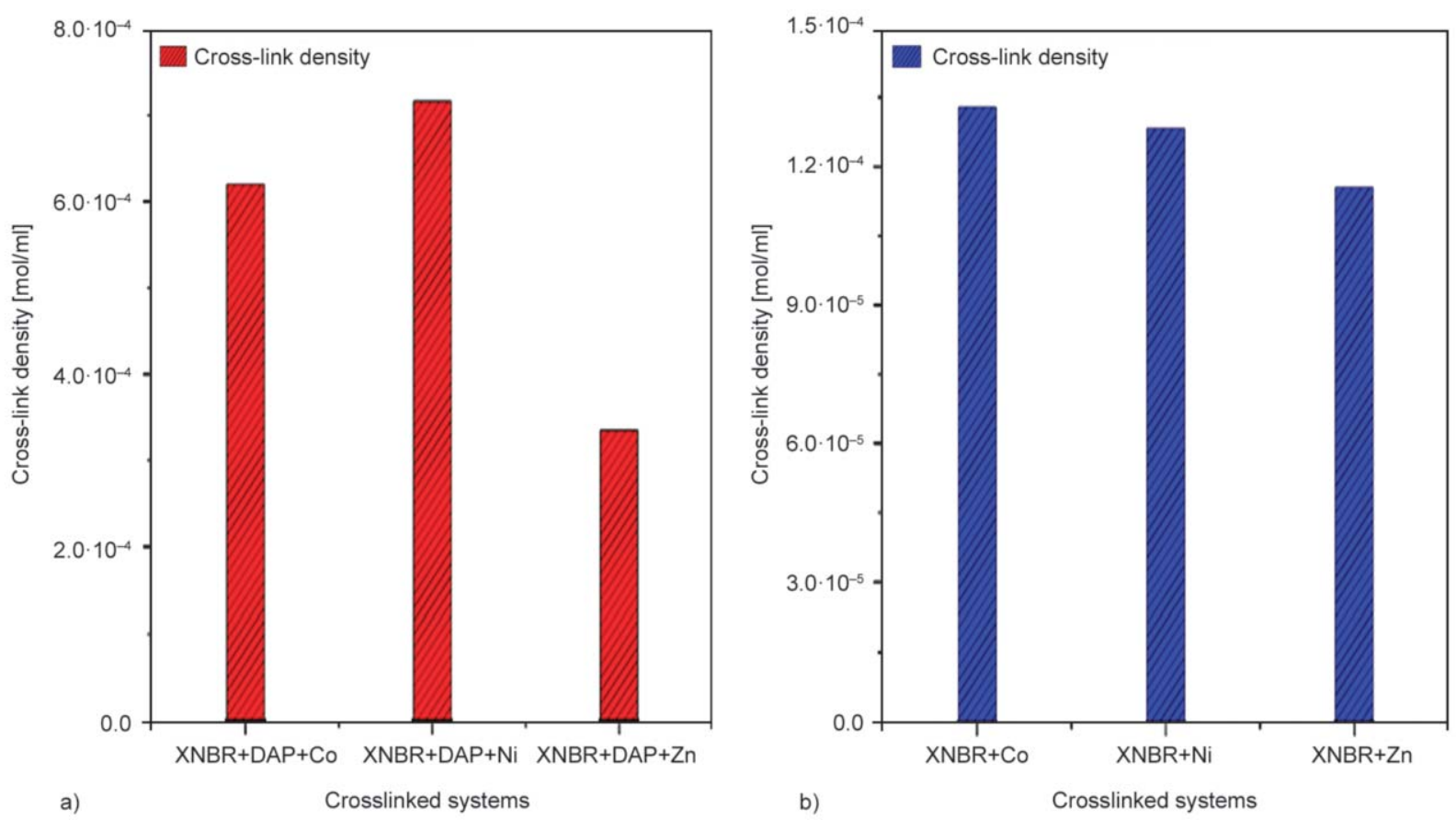

Figure 14. The cross-link density of various rubber compounds (a) XNBR with various metal ions-ligand cross-link system and (b) XNBR rubber with various metal ions systems.

due to good metal-ligand interaction into the polymer backbone. But the XNBR+DAP compound is soluble in toluene, which indicated that DAP ligand could only form an amide bond between the $-\mathrm{COOH}$ group and $\mathrm{NH}_{2}$ group of the DAP ligand and that also confirmed from FT-IR analysis.

\subsection{Optical microscopy study}

The mending of the damaged surface of various samples was observed by using an optical microscope. The images of XNBR-DAP $/ \mathrm{Zn}^{2+}, \mathrm{XNBR}-\mathrm{DAP} / \mathrm{Ni}^{2+}$, and XNBR-DAP $/ \mathrm{Co}^{2+}$ samples were compared after $24 \mathrm{~h}$ of a healing process that carried out at $80^{\circ} \mathrm{C}$ (Figure 15). The width of the damaged surface is noticeably reduced, presumably due to the highly dynamic metal-ligand coordination bonding that exists with the XNBR-DAP/metal system. The reference sample Figures $15 \mathrm{a}$ and $15 \mathrm{~b}$, which is not healed before and after the healing process at $80^{\circ} \mathrm{C}$ temperature for 24 hours.

\subsection{Atomic force microscopy (AFM) study}

The mending of the damaged surface of $\mathrm{XNBR}+\mathrm{DAP}+\mathrm{Zn}^{2+}$ sample, which exhibits $100 \%$ healing efficiency, was followed by AFM study. The probe microscopic images, that take over the damaged surface of the sample, were compared after the whole mending period (Figure 16). The $\mathrm{XNBR}+\mathrm{DAP}+\mathrm{Zn}^{2+}$ compound exhibits the best healing efficiency and hence we have taken the only $\mathrm{XNBR}+\mathrm{DAP}+\mathrm{Zn}^{2+}$ sample for the AFM study. The image shows that the compound is clearly healed after treatment at $80^{\circ} \mathrm{C}$ for 24 hours. The optical microscopic (Figure 15) and AFM study prove that the $\mathrm{XNBR}+\mathrm{DAP}+\mathrm{Zn}^{2+}$ specimen was completely healed after $24 \mathrm{~h}$ at $80^{\circ} \mathrm{C}$ due to a highly dynamic metalligand bond formation.

\subsection{Scanning electron microscopy (SEM) study}

The morphology study of a fractured surface of pristine XNBR (a), the pure DAP particle (b), $\mathrm{XNBR}+\mathrm{DAP}(\mathrm{c}), \quad \mathrm{XNBR}+\mathrm{DAP}+\mathrm{Co}^{2+}(\mathrm{d})$, $\mathrm{XNBR}+\mathrm{DAP}+\mathrm{Ni}^{2+}(\mathrm{e})$, and the $\mathrm{XNBR}+\mathrm{DAP}+\mathrm{Zn}^{2+}$ (f) compounds are shown in Figure 17. In the image of XNBR+DAP without metal ions, the ligand particles are uniformly dispersed into the matrix. But after the addition of various metal ion into the rubber matrix, to form good metal-ligand coordination, which is clearly observed into the images (Figure 17d, 17e, and 17f). In the image of $\mathrm{XNBR}+\mathrm{DAP}+\mathrm{Co}^{2+}$, $\mathrm{XNBR}+\mathrm{DAP}+\mathrm{Ni}^{2+}$, and $\mathrm{XNBR}+\mathrm{DAP}+\mathrm{Zn}^{2+}$ with the different metal ions, the ligand particles, and the metal ions are thickly and uniformly dispersed into 
Before healing

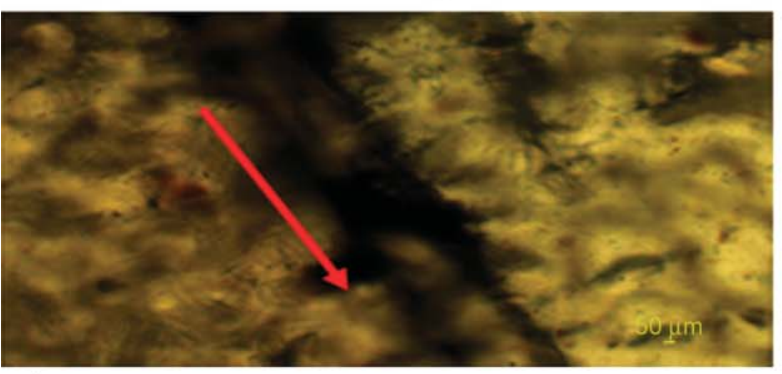

a)

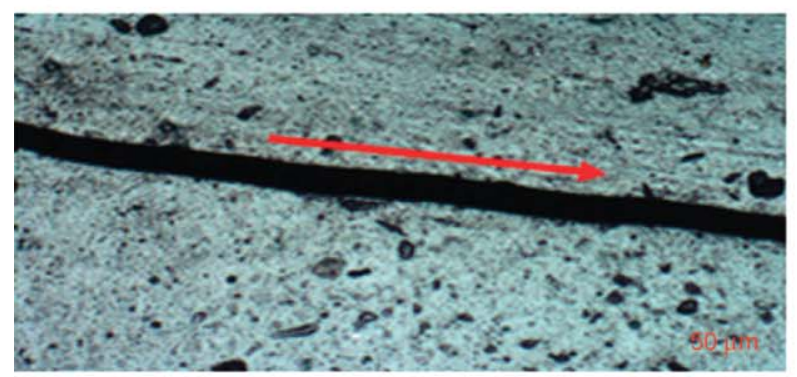

c)

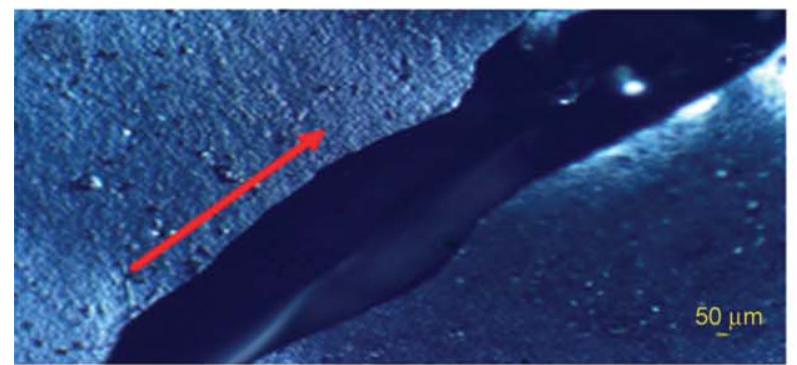

e)

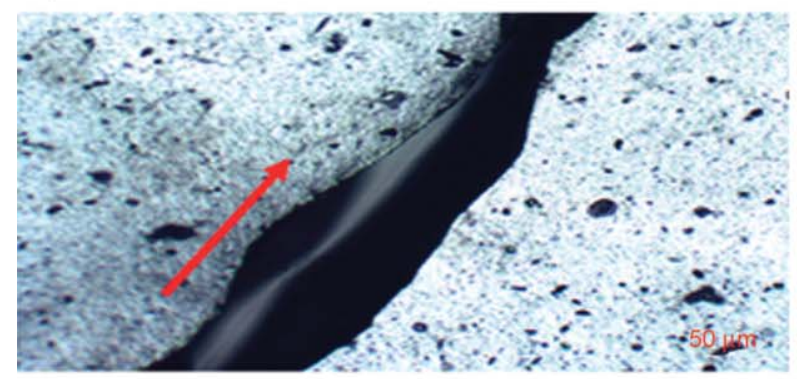

g)
After healing

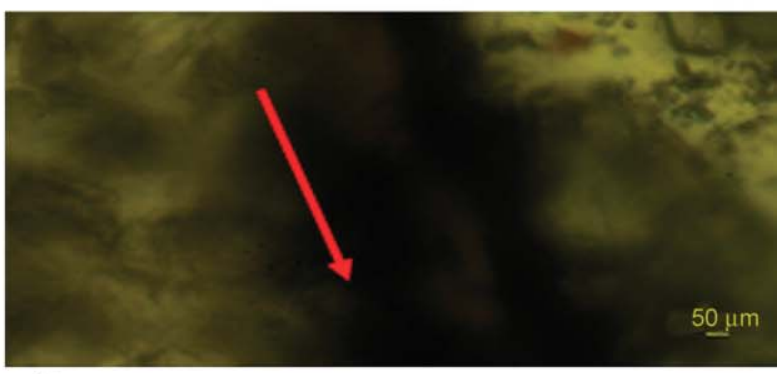

b)

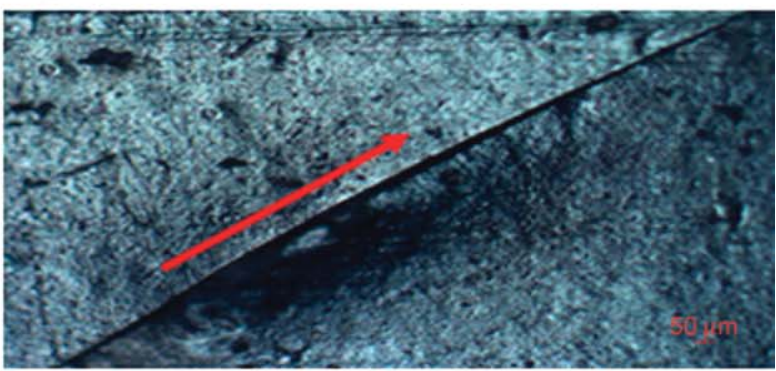

d)

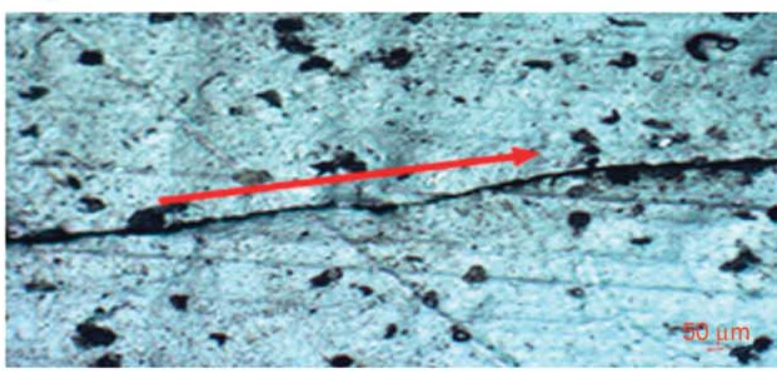

f)

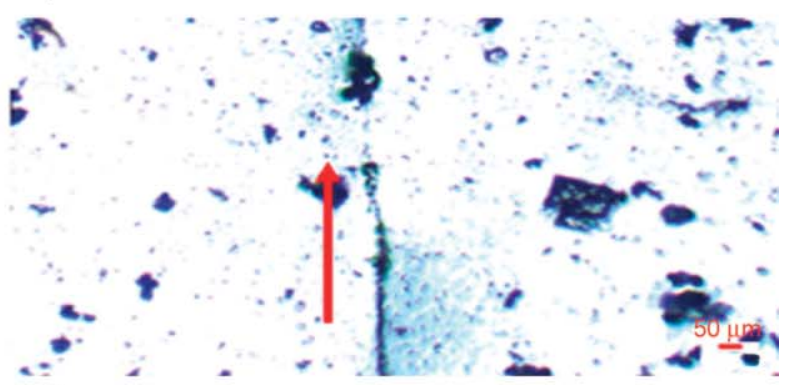

h)

Figure 15. The optical microscope images of XNBR+DAP (Reference sample) XNBR-DAP $/ \mathrm{Ni}^{2+}, \mathrm{XNBR}-\mathrm{DAP} / \mathrm{Co}^{2+}$, and the XNBR-DAP/Zn ${ }^{2+}$ sample before healing (a, c, e, and g) and the XNBR+DAP XNBR-DAP/Ni ${ }^{2+}, \mathrm{XNBR}-$ $\mathrm{DAP} / \mathrm{Co}^{2+}$, and the XNBR-DAP/ $/ \mathrm{Zn}^{2+}$ sample after healing $(\mathrm{b}, \mathrm{d}, \mathrm{f}$, and $\mathrm{h}$ ) and the red arrow is indicated the cut marked.

the matrix. The good interaction of DAP ligand with various metal ions into the XNBR matrix gives better mechanical properties and good self-healing behavior. The good metal-ligand interaction and dispersion in the matrix are clearly observed in the figure.

Energy dispersive X-ray (EDX) study

The energy dispersive $X$-ray study of a fractured surface (a) $\mathrm{XNBR}+\mathrm{DAP}$, (b) $\mathrm{XNBR}+\mathrm{DAP}+\mathrm{Co}^{2+}$, (c) $\mathrm{XNBR}+\mathrm{DAP}+\mathrm{Ni}^{2+}$, and (d) $\mathrm{XNBR}+\mathrm{DAP}+\mathrm{Zn}^{2+}$ compounds are shown in Figure 18. From the EDX analysis, it clearly observed that various metal ions are present into metal-ligand modified rubber composites, but in the case of XNBR+DAP compound, the metal ion is absent.

\subsection{High-resolution transmission electron microscopy (HR-TEM) study}

The morphology study of XNBR+DAP, $\mathrm{XNBR}+\mathrm{DAP}+\mathrm{Co}^{2+}, \mathrm{XNBR}+\mathrm{DAP}+\mathrm{Ni}^{2+}$, and the
R6

R7

$\mathrm{R} 1$

$\mathrm{R} 2$

R3

R4 

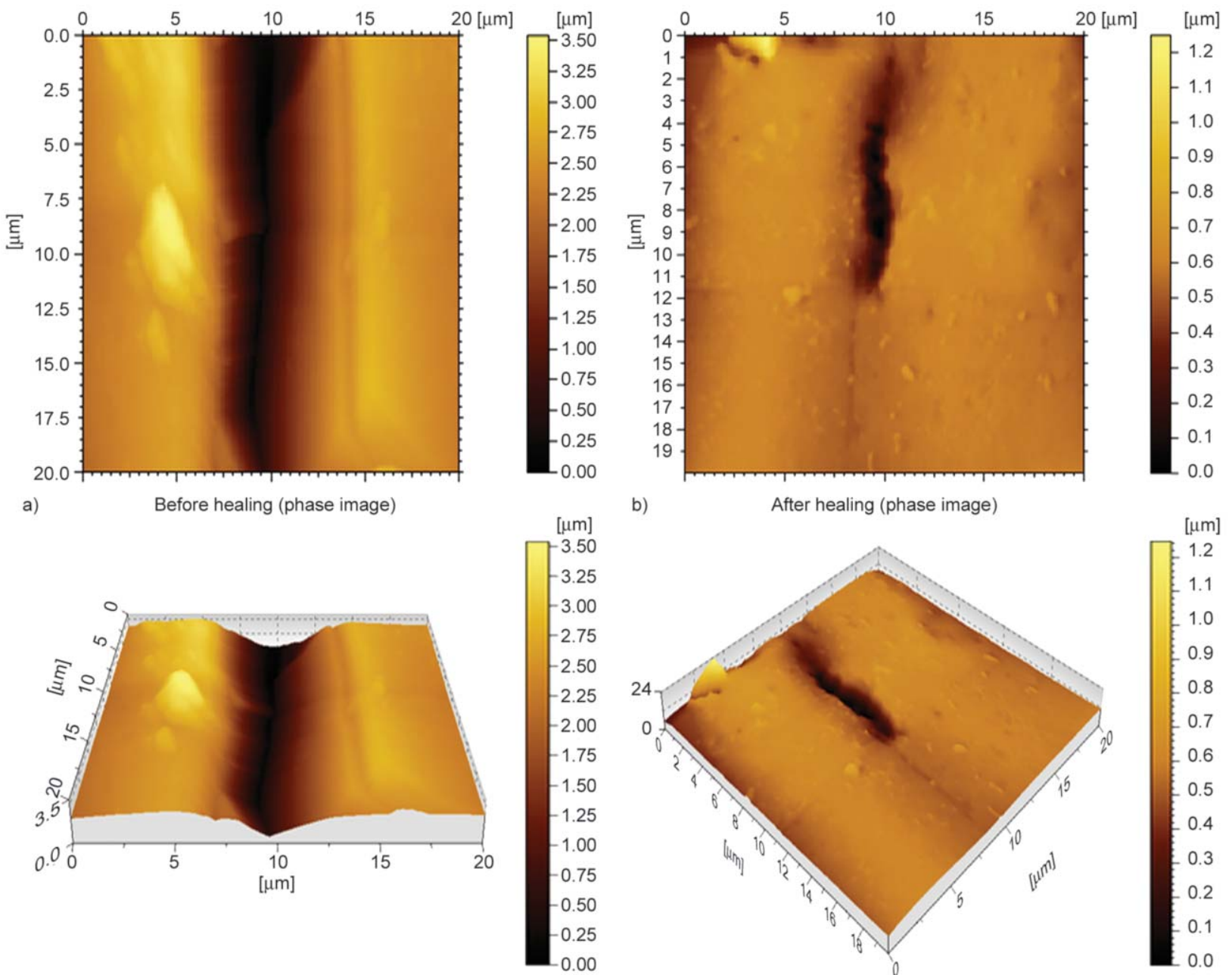

b)

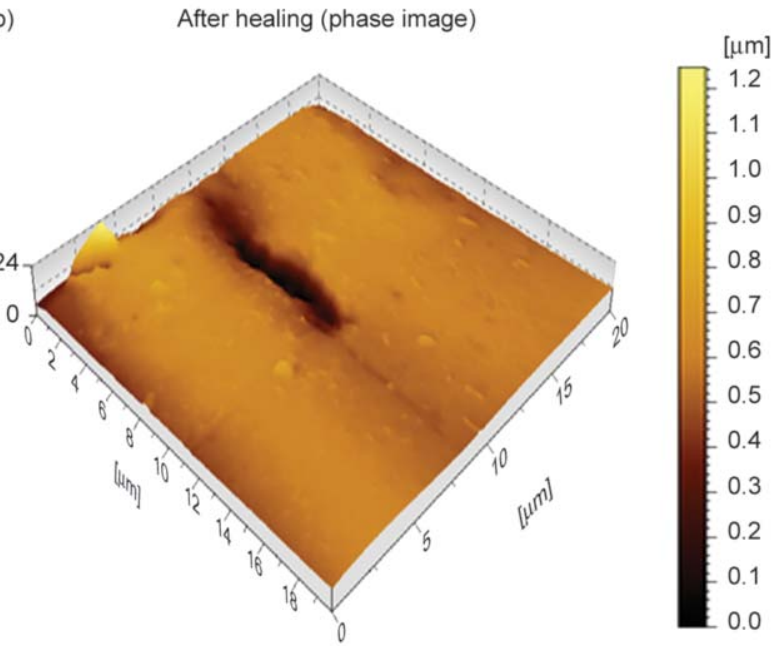

c) Before healing (3D image)

d)

After healing (3D image)

Figure 16. The AFM image of $\mathrm{XNBR}+\mathrm{DAP}+\mathrm{Zn}^{2+}$ sample. (a) and c) before and b) and d) after healing).

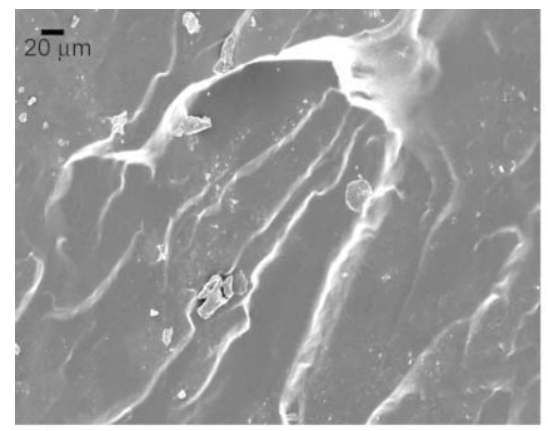

a)

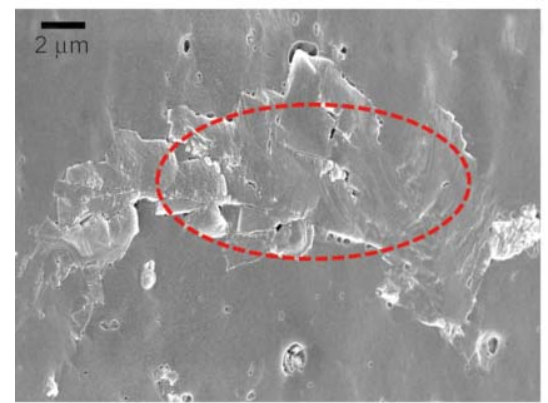

d)

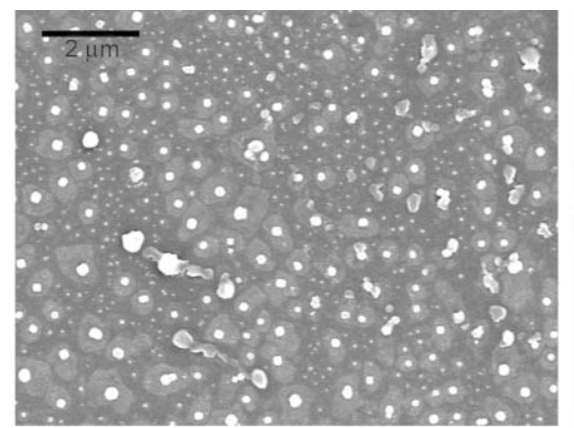

b)

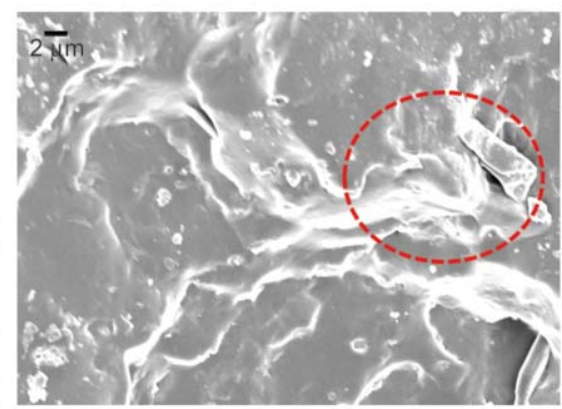

e)

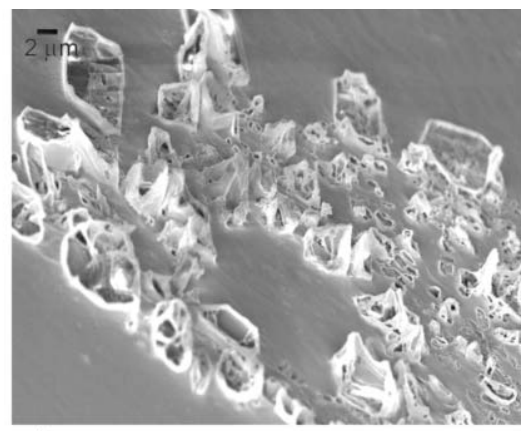

c)

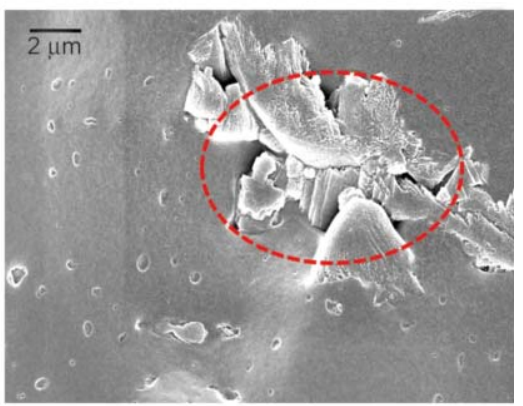

f)

Figure 17. The SEM images of pristine XNBR (a), (b) the pure DAP particle, (c) XNBR+DAP, (d) $\mathrm{XNBR}+\mathrm{DAP}+\mathrm{Co}{ }^{2+}$, (e) $\mathrm{XNBR}+\mathrm{DAP}+\mathrm{Ni}^{2+}$, and (f) the $\mathrm{XNBR}+\mathrm{DAP}+\mathrm{Zn}^{2+}$ compounds. 

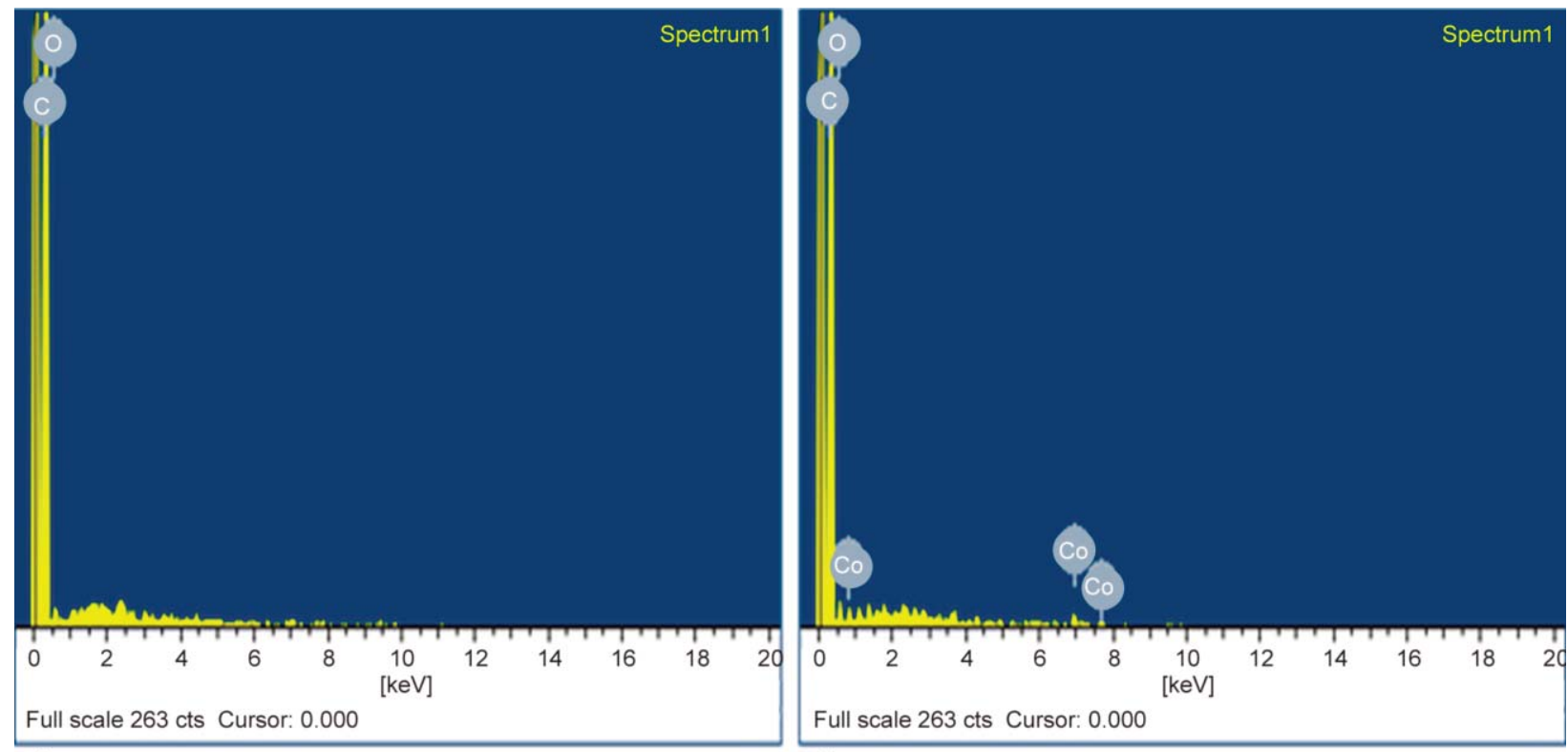

a)

b)
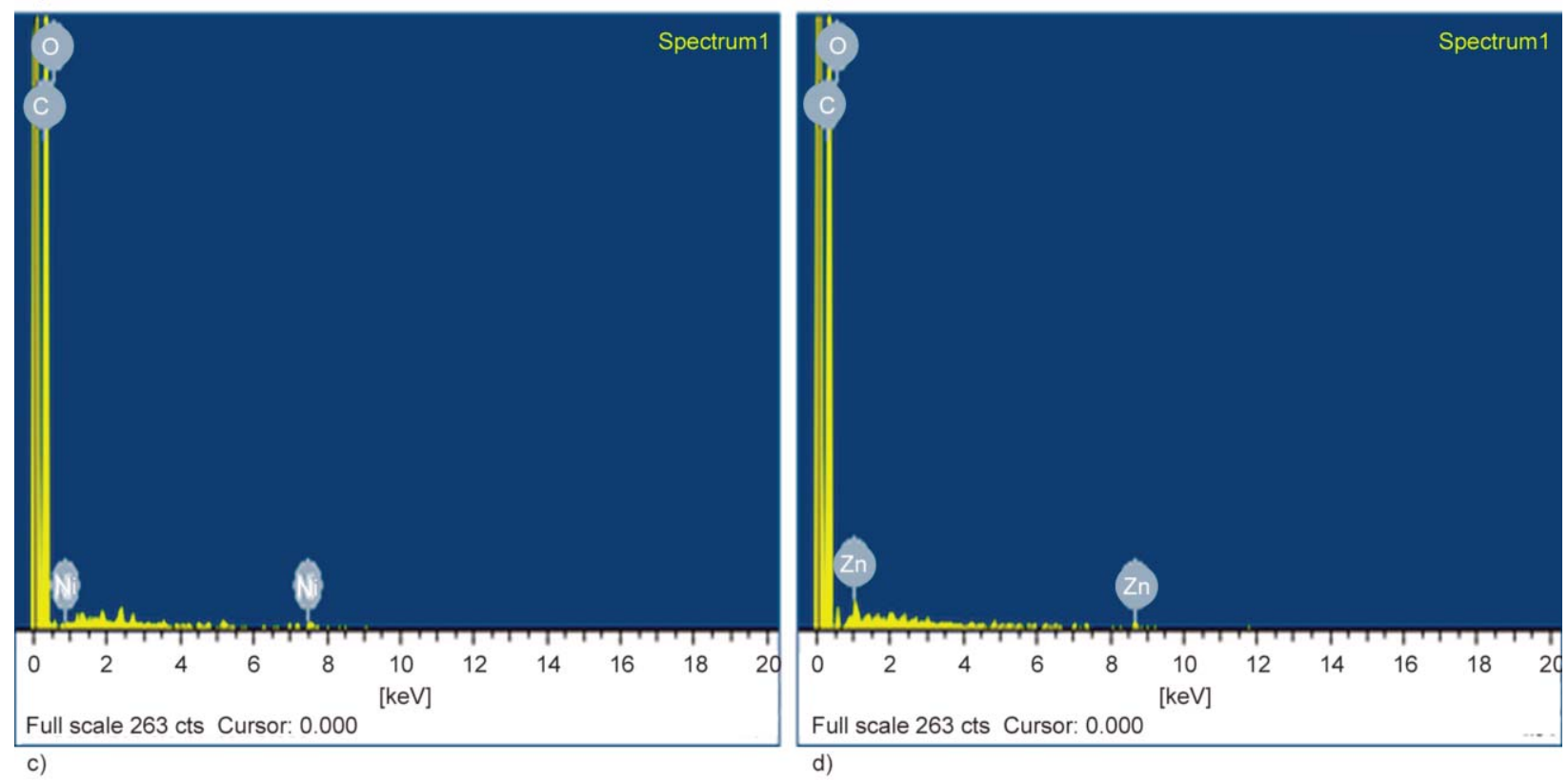

Figure 18. The EDX analysis of $\mathrm{XNBR}+\mathrm{DAP}(\mathrm{a}), \mathrm{XNBR}+\mathrm{DAP}+\mathrm{Co}^{2+}(\mathrm{b}), \mathrm{XNBR}+\mathrm{DAP}+\mathrm{Ni}^{2+}$ (c) and (d) $\mathrm{XNBR}+\mathrm{DAP}+\mathrm{Zn}{ }^{2+}$ compounds.

$\mathrm{XNBR}+\mathrm{DAP}+\mathrm{Zn}^{2+}$ are shown in Figure 19. In the image of XNBR+DAP compound, the ligand particles are uniformly dispersed and easily seen into a rubber matrix. After the addition of various metal ions on the XNBR+DAP system, the structure changes due to metal-ligand interaction, to form good metal-ligand coordination and well dispersion of the various metal ions and DAP ligands into rubber matrix, which is clearly observed into images $(b$, $\mathrm{c}$, and d). The TEM image shows that good interaction of DAP ligand with various metal ions into the XNBR matrix gives better mechanical properties and good self-healing behavior. The SEM (Figure 17) and TEM analysis are strong evidence that well dispersion and good coordination of various metal ions and ligand particles.

\section{Conclusions}

In this study, we have demonstrated a new self-healing rubber based on the metal-ligand coordination between DAP ligand and different metal ions $\mathrm{CO}^{2+}$, $\mathrm{Ni}^{2+}$, and $\mathrm{Zn}^{2+}$ ) moieties incorporated into the XNBR backbone. The formation of amide linkage and metalligand coordination bonds into the rubber backbone is confirmed by the FTIR analysis. The strength of the different metal ion-DAP ligand coordination 


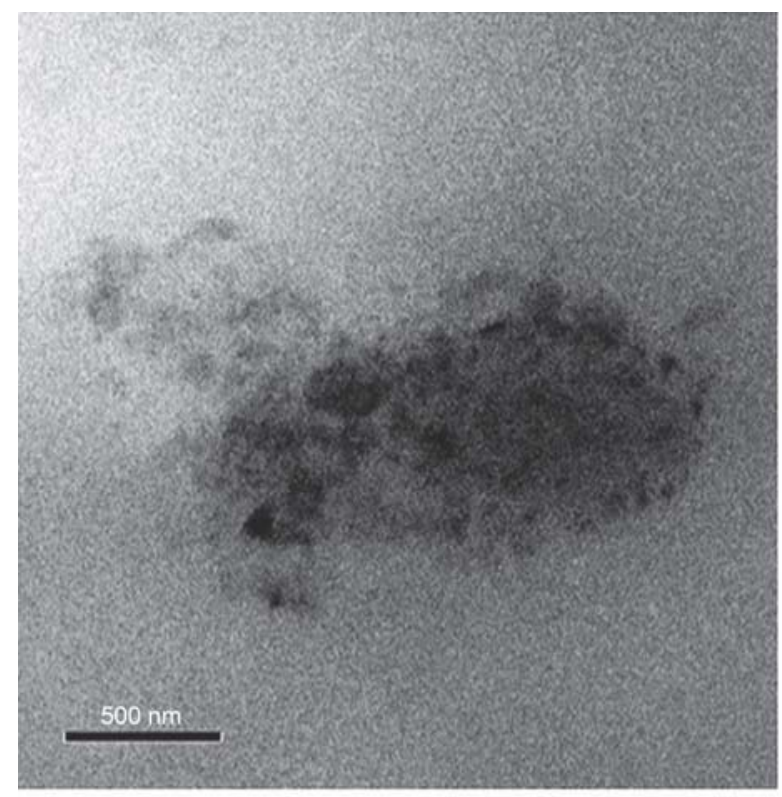

a)

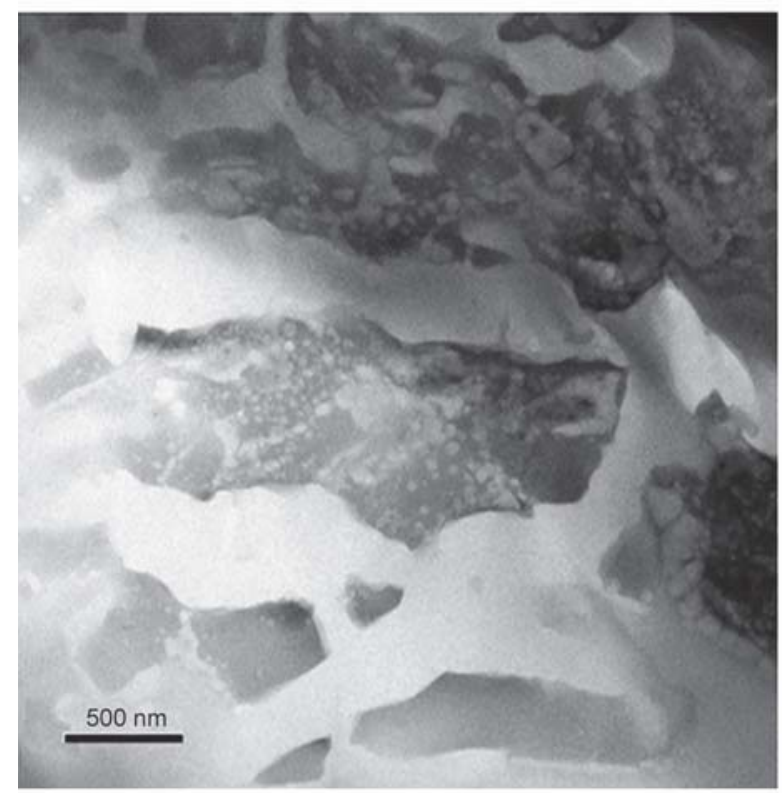

c)

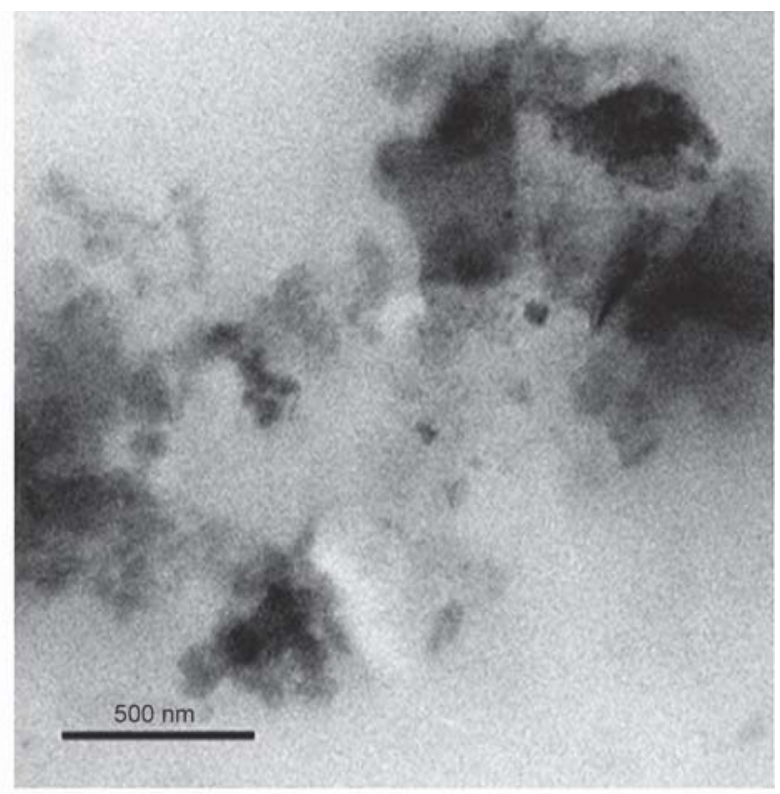

b)

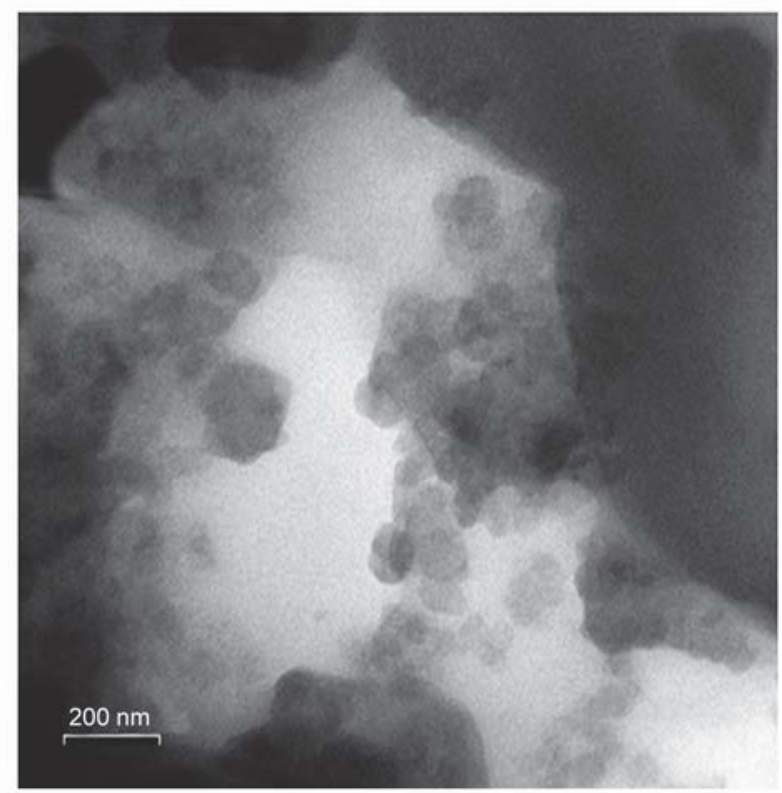

d)

Figure 19. The TEM images of $\mathrm{XNBR}+\mathrm{DAP}(\mathrm{a}), \mathrm{XNBR}+\mathrm{DAP}+\mathrm{Co}^{2+}(\mathrm{b}), \mathrm{XNBR}+\mathrm{DAP}+\mathrm{Ni}^{2+}$ (c) and (d) $\mathrm{XNBR}+\mathrm{DAP}+\mathrm{Zn}{ }^{2+}$ compounds.

bonds depends on the type of metal ions. The selfhealing ability of rubber composite is mainly determined by the lability and dynamic nature of metalligand bonds. We found that XNBR-DAP/ $/ \mathrm{Zn}^{2+}$ compound exhibited the $100 \%$ healing efficiency with the tensile strength of $4.3 \pm 0.6 \mathrm{MPa}$ because of very dynamic character of $\mathrm{Zn}-\mathrm{DAP}$ bond and XNBR-DAP $/ \mathrm{Co}^{2+}$ sample showed a good healing efficiency of $88 \%$ with excellent tensile strength of $10.3 \pm 1.1 \mathrm{MPa}$, due to the dynamic feature of CoDAP bond. While for the XNBR-DAP/Ni ${ }^{2+}$ compound, the poor healing efficiency is noticed because of the strong Ni-DAP bond and after self-healing, the metal-ligand coordination bond was formed. This finding is confirmed by the DSC, FTIR and the stress relaxation (RPA 2000) results reported in this work. The approach of changing commercial rubber into the self-healing purpose by developing multiple metal-ligand crosslinking networks and which is the new technologies for the acceptable application of the cross-linked rubber products. The various metalDAP bonds are in stumble during healing, after that the metal ion is still joined to the ligand by the strong metal-pyridine bond and which is permitting the carboxylated nitrile rubber with the quick and excellent self-healing capability. 


\section{Acknowledgements}

Authors cordially acknowledge the financial support from the Indian Institute of Technology (IIT) Kharagpur (India). The state of the art research facility at the Rubber Technology Centre at IIT Kharagpur is also acknowledged. We are very grateful to our research co-workers, Anagha M G, Asit Baran Bhattacharya, Aswathy T. Raju and Sreethu T. K for their technical support in this work.

\section{References}

[1] Liu J., Wang S., Tang Z., Huang J., Guo B., Huang G.: Bioinspired engineering of two different types of sacrificial bonds into chemically cross-linked cis-1,4-polyisoprene toward a high-performance elastomer. Macromolecules, 49, 8593-8604 (2016).

https://doi.org/10.1021/acs.macromol.6b01576

[2] Bartlett M. D., Dickey M. D., Majidi C.: Self-healing materials for soft-matter machines and electronics. NPG Asia Materials, 11, 21/1-21/4 (2019). https://doi.org/10.1038/s41427-019-0122-1

[3] Li G., Xiao P., Hou S., Huang Y.: Graphene based selfhealing materials. Carbon, 146, 371-387 (2019). https://doi.org/10.1016/j.carbon.2019.02.011

[4] Wang Z., Xie C., Yu C., Fei G.,Wang Z., Xia H.: A facile strategy for self-healing polyurethanes containing multiple metal-ligand bonds. Macromolecular Rapid Communications, 39, 1700678/1-1700678/7 (2018). https://doi.org/10.1002/marc.201700678

[5] Qiao H., Qi P., Zhang X., Wang L., Tan Y., Luan Z., Xia Y., Li Y., Sui K.: Multiple weak H-bonds lead to highly sensitive, stretchable, self-adhesive, and self-healing ionic sensors. ACS Applied Materials and Interfaces, 11, 7755-7763 (2019). https://doi.org/10.1021/acsami.8b20380

[6] White S. R., Sottos N. R., Geubelle P. H., Moore J. S., Kessler M. R., Sriram S. R., Brown E. N., Viswanathan S.: Autonomic healing of polymer composites. Nature, 409, 794-797 (2001). https://doi.org/10.1038/35057232

[7] Kim C., Ejima H., Yoshie N.: Polymers with autonomous self-healing ability and remarkable reprocessability under ambient humidity conditions. Journal of Materials Chemistry A, 6, 19643-19652 (2018). https://doi.org/10.1039/C8TA04769c

[8] D’Elia E., Eslava S., Miranda M., Georgiou T. K., Saiz E.: Autonomous self-healing structural composites with bio-inspired design. Scientific Reports, 6, 25059/125059/11 (2016). https://doi.org/10.1038/srep25059

[9] Toohey K. S., Sottos N. R., Lewis J. A., Moore J. S., White S. R.: Self-healing materials with microvascular networks. Nature Materials, 6, 581-585 (2007). https://doi.org/10.1038/nmat1934

[10] Peng Y., Zhao L., Yang C., Yang Y., Song C., Wu Q., Huang G., Wu J.: Super tough and strong self-healing elastomers based on polyampholytes. Journal of Materials Chemistry A, 6, 19066-19074 (2018).

https://doi.org/10.1039/C8TA06561f
[11] Liu Y., Li Z., Liu R., Liang Z., Yang J., Zhang R., Zhou Z., Nie Y.: Design of self-healing rubber by introducing ionic interaction to construct a network composed of ionic and covalent cross-linking. Industrial and Engineering Chemistry Research, 58, 14848-14858 (2019). https://doi.org/10.1021/acs.iecr.9b02972

[12] Xu C., Nie J., Wu W., Zheng Z., Chen Y.: Self-healable, recyclable, and strengthened epoxidized natural rubber/carboxymethyl chitosan biobased composites with hydrogen bonding supramolecular hybrid networks. ACS Sustainable Chemistry and Engineering, 7, 1577815789 (2019).

https://doi.org/10.1021/acssuschemeng.9b04324

[13] Terryn S., Brancart J., Lefeber D., Van Assche G., Vanderborght B.: Self-healing soft pneumatic robots. Science Robotics, 2, eaan4268/1-eaan4268/12 (2017). https://doi.org/10.1126/scirobotics.aan4268

[14] Habault D., Zhang H., Zhao Y.: Light-triggered selfhealing and shape-memory polymers. Chemical Society Reviews, 42, 7244-7256 (2013). https://doi.org/10.1039/C3CS35489J

[15] Hinton Z. R., Shabbir A., Alvarez N. J.: Dynamics of supramolecular self-healing recovery in extension. Macromolecules, 52, 2231-2242 (2019).

https://doi.org/10.1021/acs.macromol.8b02423

[16] Moniruzzaman M., Christogianni P., Kister G.: Selfhealing in epoxy thermoset polymer films triggered by UV ILight. Procedia Engineering, 148, 114-121 (2016). https://doi.org/10.1016/j.proeng.2016.06.472

[17] Amamoto Y., Kamada J., Otsuka H., Takahara A., Matyjaszewski K.: Repeatable photoinduced self-healing of covalently cross-linked polymers through reshuffling of trithiocarbonate units. Angewandte Chemie International Edition, 50, 1660-1663 (2011). https://doi.org/10.1002/anie.201003888

[18] Rekondo A., Martin R., Ruiz de Luzuriaga A., Cabañero G., Grande H. J., Odriozola I.: Catalyst-free room-temperature self-healing elastomers based on aromatic disulfide metathesis. Materials Horizons, 1, 237-240 (2014).

https://doi.org/10.1039/C3MH00061c

[19] Yang Y., Urban M. W.: Self-healing of polymers via supramolecular chemistry. Advanced Materials Interfaces, 5, 1-19 (2018). https://doi.org/10.1002/admi.201800384

[20] Pal S., Das M., Naskar K.: Exploring copper-amino acid complexes in cross-linking of maleated ethylene propylene rubber. Industrial and Engineering Chemistry Research, 58, 17802-17813 (2019). https://doi.org/10.1021/acs.iecr.9b03254

[21] Nomimura S., Osaki M., Park J., Ikura R., Takashima Y., Yamaguchi H., Harada A.: Self-healing alkyl acrylatebased supramolecular elastomers cross-linked via hostguest interactions. Macromolecules, 52, 2659-2668 (2019). https://doi.org/10.1021/acs.macromol.9b00471 
[22] Hou J-B., Zhang X-Q., Wu D., Feng J-F., Ke D., Li B-J., Zhang S.: Tough self-healing elastomers based on the host-guest interaction of polycyclodextrin. ACS Applied Materials and Interfaces, 11, 12105-12113 (2019). https://doi.org/10.1021/acsami.9b00626

[23] Xu C., Cao L., Huang X., Chen Y., Lin B., Fu L.: Selfhealing natural rubber with tailorable mechanical properties based on ionic supramolecular hybrid network. ACS Applied Materials and Interfaces, 9, 29363-29373 (2017). https://doi.org/10.1021/acsami.7b09997

[24] Das A., Sallat A., Böhme F., Suckow M., Basu D., Wießner S., Stöckelhuber K. W., Voit B., Heinrich G.: Ionic modification turns commercial rubber into a selfhealing material. ACS Applied Materials and Interfaces, 7, 20623-20630 (2015). https://doi.org/10.1021/acsami.5b05041

[25] Kammakakam I., O’Harra K. E., Dennis G. P., Jackson E. M., Bara J. E.: Self-healing imidazolium-based ionene-polyamide membranes: An experimental study on physical and gas transport properties. Polymer International, 68, 1123-1129 (2019). https://doi.org/10.1002/pi.5802

[26] Cui X., Song Y., Wang J-P., Wang J-K., Zhou Q., Qi T., Li G. L.: Self-healing polymers with tunable mechanical strengths via combined hydrogen bonding and zincimidazole interactions. Polymer, 174, 143-149 (2019). https://doi.org/10.1016/j.polymer.2019.04.060

[27] Li G., Xiao P., Hou S., Huang Y.: Rapid and efficient polymer/graphene based multichannel self-healing material via Diels-Alder reaction. Carbon, 147, 398-407 (2019). https://doi.org/10.1016/j.carbon.2019.03.021

[28] Oh C-R., Lee S-H., Park J-H., Lee D-S.: Thermally self-healing graphene-nanoplate/polyurethane nanocomposites via Diels-Alder reaction through a one-shot process. Nanomaterials, 9, 434-346 (2019). https://doi.org/10.3390/nano9030434

[29] Behera P. K., Mondal P., Singha N. K.: Self-healable and ultrahydrophobic polyurethane-poss hybrids by Diels-Alder 'click'reaction: A new class of coating material. Macromolecules, 51, 4770-4781 (2018). https://doi.org/10.1021/acs.macromol.8b00583

[30] Latif S., Amin S., Haroon S. S., Sajjad M. I. A.: Selfhealing materials for electronic applications: An overview. Materials Research Express, 6, 062001/1062011/6 (2019).

https://doi.org/10.1088/2053-1591/ab0f4c

[31] Du G., Mao A., Yu J., Hou J., Zhao N., Han J., Zhao Q., Gao W., Xie T., Bai H.: Nacre-mimetic composite with intrinsic self-healing and shape-programming capability. Nature Communications, 10, 1-8 (2019). https://doi.org/10.1038/s41467-019-08643-x
[32] Zhang B., Zhang W., Zhang Z., Zhang Y-F., Hingorani H., Liu Z., Liu J., Ge Q.: Self-healing four-dimensional printing with an ultraviolet curable double-network shape memory polymer system. ACS Applied Materials and Interfaces, 11, 10328-10336 (2019).

https://doi.org/10.1021/acsami.9b00359

[33] Cheng Z., Yan M., Cao L., Huang J., Cao X., Yuan D., Chen Y.: Design of nitrile rubber with high strength and recycling ability based on $\mathrm{Fe}^{3+}$-catechol group coordination. Industrial and Engineering Chemistry Research, 58, 3912-3920 (2019).

https://doi.org/10.1021/acs.iecr.8b05993

[34] Cheng B., Lu X., Zhou J., Qin R., Yang Y.: Dual crosslinked self-healing and recyclable epoxidized natural rubber based on multiple reversible effects. ACS Sustainable Chemistry and Engineering, 7, 4443-4455 (2019).

https://doi.org/10.1021/acssuschemeng.8b06437

[35] Vermonden T., van der Gucht J., de Waard P., Marcelis A. T. M., Besseling N. A. M., Sudhölter E. J. R., Fleer G. J., Cohen Stuart M. A.: Water-soluble reversible coordination polymers: Chains and rings. Macromolecules, 36, 7035-7044 (2003).

https://doi.org/10.1021/ma030353t

[36] Jiang F., Zhang X., Hwang W., Briber R. M., Fang Y., Wang H.: Supramolecular luminescent triblock copolymer thermoplastic elastomer via metal-ligand coordination. Polymer Testing, 78, 105956/1-105956/8 (2019). https://doi.org/10.1016/j.polymertesting.2019.105956

[37] Zhang X., Tang Z., Guo B., Zhang L.: Enabling design of advanced elastomer with bioinspired metal-oxygen coordination. ACS Applied Materials and Interfaces, 8, 32520-32527 (2016). https://doi.org/10.1021/acsami.6b10881

[38] Basu D., Das A., Stöckelhuber K. W., Jehnichen D., Formanek P., Sarlin E., Vuorinen J., Heinrich G.: Evidence for an in situ developed polymer phase in ionic elastomers. Macromolecules, 47, 3436-3450 (2014). https://doi.org/10.1021/ma500240v

[39] Trivedi M. K., Branton A., Trivedi D., Nayak G., Mishra R., Jana S.: Characterization of physical, thermal and spectral properties of biofield treated 2-aminopyridine. Science Journal of Analytical Chemistry, 3, 127-134 (2015). https://doi.org/10.11648/j.sjac.20150306.18

[40] Mamo A., Finocchiaro P., Bottino F., Pappalardo S.: Synthesis and characterization of polyamides and polyureas with acyclic and cyclic bipyridinediyl diamino structures in the polymer backbone. Journal of Polymer Science Part A: Polymer Chemistry, 28, 2237-2247 (1990). https://doi.org/10.1002/pola.1990.080280901 